\title{
CrystEngComm
}

Check for updates

Cite this: CrystEngComm, 2019, 21, 3502

Received 27th April 2019,

Accepted 13th May 2019

DOI: $10.1039 / \mathrm{c} 9 \mathrm{ce} 00633 \mathrm{~h}$

rsc.li/crystengcomm

\section{An XRD and NMR crystallographic investigation of the structure of 2,6-lutidinium hydrogen fumarate $\dagger$}

\author{
Emily K. Corlett, ${ }^{a}$ Helen Blade, ${ }^{b}$ Leslie P. Hughes, (DD ${ }^{b}$ Philip J. Sidebottom, ${ }^{c}$ \\ David Walker, (iD ${ }^{a}$ Richard I. Walton (iD ${ }^{d}$ and Steven P. Brown (iD $* a$
}

\begin{abstract}
Fumarate is a pharmaceutically acceptable counterion often used to modify the biophysical properties of active pharmaceutical ingredients (APIs) through salt formation. With 2,6-lutidine (2,6-dimethylpyridine), fumaric acid forms the salt 2,6-lutidinium hydrogen fumarate. An NMR crystallography approach was employed to investigate the salt structure and the intermolecular interactions involved in its formation and stability. The crystallographic unit cell was determined by both single crystal XRD (SXRD) and synchrotron powder X-ray diffraction (PXRD) to contract at low temperature with a skew in the $\beta$ angle. Density functional theory (DFT)-based geometry optimisations were found partially to replicate this. A second room temperature structure was also identified which exhibited a similar skew of the $\beta$ angle as the low temperature structure. DFT calculation was also employed, alongside $2 \mathrm{D}{ }^{1} \mathrm{H}$ double-quantum (DQ) magic angle spinning (MAS) and ${ }^{14} \mathrm{~N}-{ }^{1} \mathrm{H}$ HMQC MAS NMR spectra, to investigate the hydrogen bonding network involved in the structure. DFT-based gauge-including projector-augmented wave (GIPAW) calculations highlighted both strong $\mathrm{N}^{+}-\mathrm{H} \cdots \mathrm{O}^{-}$and $\mathrm{O}-\mathrm{H} \cdots \mathrm{O}$ intermolecular hydrogen bonds between the molecules, as well as several weaker $\mathrm{CH} \cdots \mathrm{O}$ hydrogen bonds. Both PXRD and solid-state MAS NMR, supported by thermal gravimetric analysis (TGA) and solution-state NMR analysis, show formation of fumaric acid within samples over time. This was evidenced by the identification of reflections and peaks associated with crystalline fumaric acid in the PXRD pattern and in ${ }^{1} \mathrm{H}$ MAS and ${ }^{13} \mathrm{C}$ cross polarization (CP) MAS solid-state NMR spectra, respectively.
\end{abstract}

\section{Introduction}

The analytical characterisation of the solid-state structures adopted by an active pharmaceutical ingredient (API) or agrochemical ingredient (AI) is an important step in the process of optimising the design and efficacy of products. A key area of research pertains to methods of enhancing an API's and AI's physical properties without detrimentally affecting its bioactivity. Increasingly, the APIs being developed are larger and more insoluble. ${ }^{1,2}$ Thus, developing approaches to improve their solubility and rate of dissolution are of particular importance. The development of salt forms offers the possibility of altering biophysical properties, ${ }^{3}$ such as solubility, bioavailability and stability, although other methods for enabling for-

\footnotetext{
${ }^{a}$ Department of Physics, University of Warwick, Coventry, CV4 7AL, UK. E-mail: S.P.Brown@warwick.ac.uk

${ }^{b}$ Pharmaceutical Development, AstraZeneca, Macclesfield, SK10 2NA, UK ${ }^{c}$ Syngenta, Jealott's Hill, RG42 6EY, UK

${ }^{d}$ Department of Chemistry, University of Warwick, Coventry, CV4 7AL, UK

$\dagger$ Electronic supplementary information (ESI) available. CCDC 1876100. For ESI and crystallographic data in CIF or other electronic format see DOI: 10.1039/ c9ce00633h
}

mulation like co-crystallisation and rendering the material amorphous are also employed. ${ }^{2-6}$ Salts and cocrystals are often distinguished by their ionicity, with cocrystals containing neutral molecules.

One formal definition of a cocrystal, according to Dunitz, ${ }^{7}$ also includes solvates, although they can alternatively be defined separately by the physical distinction that one of the components is liquid at room temperature. ${ }^{4,8}$ Solvates are intrinsically unstable and generally undergo some form of phase change close to room temperature, ${ }^{8}$ making both their use and characterisation more challenging. They are still of interest though, as they represent another potential route to additional biologically active forms that may have desirable properties. The characterisation of such systems may also be relevant in cases where an API/AI is liquid at room temperature, but it is preferable to be able to store or administer it in solid form (for cost, convenience and/or ease of use).

Traditionally, X-ray diffraction (XRD) is employed for structure determination of crystalline materials. Single crystal XRD (SXRD) is the gold standard for organic molecules, with powder XRD (PXRD) mainly used to fingerprint or refine the resulting structure. However, where suitable single crystals 
are not available, structure determination has been achieved from powder patterns. ${ }^{9-14}$ Distinguishing between salts and cocrystal forms by XRD can be difficult, however, as it is inherently insensitive to low atomic number elements. As a result, it is not always possible to provide accurate proton positions, particularly if the quality of single crystals is poor. ${ }^{6}$ This limits the ability of XRD to give a detailed representation of the intermolecular interactions present within a system. A more thorough investigation of these interactions can inform how the crystal structure is being held together, aiding in the development of methods to reliably predict the stability of multicomponent solid forms. ${ }^{8}$

NMR crystallography ${ }^{15-19}$ is a growing field in which solidstate NMR, under magic-angle spinning (MAS), and calculations of NMR parameters from first principles using density functional theory (DFT), notably the gauge-including projector-augmented wave (GIPAW) method, are combined. ${ }^{20,21}$ It complements other techniques (generally XRD) to either facilitate structure determination, ${ }^{9,16,22-24}$ interrogate the nature of both weak and strong intermolecular interactions ${ }^{25-28}$ or investigate the structure of localised disorder within systems. ${ }^{29}$ NMR crystallography of organic systems benefits particularly from the intrinsic sensitivity of ${ }^{1} \mathrm{H}$ chemical shifts to local interactions. ${ }^{30}$

In this work, NMR, XRD and DFT are combined and utilised to investigate the intermolecular interactions and stability of 2,6-lutidinium hydrogen fumarate. ${ }^{31}$ Fumarate is a pharmaceutically acceptable counterion for salt formation and is already employed to improve the properties of various APIs, including ferrous iron, bisoprolol and tenofovir disoproxil. ${ }^{32}$ Fumaric acid is a crystalline solid at room temperature and can exist in a variety of crystal forms with different isomers of lutidine, as investigated by Haynes et al. ${ }^{33}$ Conversely, 2,6-lutidine is liquid at room temperature, which allows the system to be described as either a API/AI-fumarate or as a solvate.

\section{Experimental}

\section{Sample preparation}

All chemicals were obtained from Sigma Aldrich (UK) at purities of $98 \%$ or higher and used without further purification. Purity was verified by ${ }^{1} \mathrm{H}$ solution-state NMR. Fumaric acid was dissolved in isopropanol and 2,6-lutidine was added in a $1: 1$ molar ratio. Samples were made on a $\sim 50 \mathrm{mg}$ scale with $24 \mathrm{mg}$ fumaric acid and $26 \mu \mathrm{L}$ 2,6-lutidine (with density 0.92 $\mathrm{mg} \mathrm{L}^{-1}$ ). Crystallisation was achieved by slow solvent evaporation over approximately 4 days.

\section{Calculations}

Density functional theory (DFT) calculations were performed using CASTEP ${ }^{34}$ Academic Release version 16.1. All calculations used the Perdew Burke Ernzerhof (PBE) exchange correlation functional, ${ }^{35}$ a plane-wave basis set with ultrasoft pseudopotentials and a plane-wave cut-off energy of $700 \mathrm{eV}$.
Integrals over the Brillouin zone were taken using a Monkhorst-Pack grid of minimum sample spacing $0.1 \times 2 \pi$ $\AA^{-1}$ (see Fig. $\mathrm{S} 1 \uparrow$ for convergence of energy with decreasing spacing). The literature structure, ${ }^{31}$ which was recorded at $292 \mathrm{~K}$, was downloaded from the Cambridge Crystallographic Data Centre (CCDC), ${ }^{36}$ CCDC ref.: MIBYEB, no.: 181445. For all structures for which the NMR parameters were calculated, geometry optimisation was performed with the unit cell parameters fixed. Geometry optimisations were also run for each structure allowing the unit cell parameters to vary, with a dispersion correction applied under the scheme proposed by Tkatchenko and Scheffler. ${ }^{37}$ MOGUL $^{38}$ searches were performed both before and after geometry optimisation to ensure that the bond lengths, torsion and angles were consistent with the CCDC database. Distances stated in this paper are for the DFT optimised structure calculated with fixed unit cell (unless otherwise stated).

NMR parameters were calculated using the GIPAW method and were performed for both the geometry optimised crystal structures as a whole and for each of the isolated molecules in the asymmetric unit. For the isolated molecule calculations, each molecule in the asymmetric unit was extracted from the geometry optimised unit cell and placed in a sufficiently large box such that it could not interact with repeated molecules across periodic boundary conditions ${ }^{28}$ (unit cell dimensions increased by $10 \AA$ in each direction). As each individual molecule carried a charge, this was specified in the param file. ${ }^{39}$

The calculated isotropic chemical shifts $\left(\delta_{\text {iso }}^{\text {calc }}\right)$ were determined from the calculated chemical shieldings $\left(\sigma_{\text {calc }}\right)$ by $\left(\delta_{\text {iso }}^{\text {calc }}\right)=\sigma_{\text {ref }}-\sigma_{\text {calc }}$, with $\sigma_{\text {ref }}$ values of $30.5,169.7$ and -153 ppm for ${ }^{1} \mathrm{H},{ }^{13} \mathrm{C}$ and ${ }^{14} \mathrm{~N}$, respectively. $\sigma_{\text {ref }}$ was determined for ${ }^{1} \mathrm{H}$ and ${ }^{13} \mathrm{C}$ by taking the sum of the experimental chemical shift and the GIPAW calculated absolute isotropic chemical shieldings. The resulting $y$-intercept was taken as $\sigma_{\text {ref }}{ }^{40,41} \mathrm{~A}$ literature value was used for ${ }^{14} \mathrm{~N} .{ }^{42}$ It is noted that it is common practice to calculate a specific reference shielding for each system ${ }^{43}$ (see, e.g., Table S8 of ref. 43), though average values over a range of compounds are also available. ${ }^{44}$ By comparing the parameters in the full crystal structure with those for the isolated molecule, insight is provided into the intermolecular interactions responsible for maintaining the crystal structure. ${ }^{45}$

\section{XRD}

Crystals were initially selected for SXRD using polarised light microscopy with an Olympus SZ61 stereomicroscope. Those that appeared by shape and birefringence to be single crystals were chosen. SXRD was carried out on a Rigaku Oxford Diffraction SuperNova diffractometer under $\mathrm{Cu} \mathrm{K} \mathrm{K}_{\alpha 1,2}(1.5418 \AA)$ with an Atlas S2 CCD detector. Crystal screening was conducted at room temperature. CrysAlisPro ${ }^{46}$ data-collection and processing software was used, allowing crystals to be checked for quality and giving a preliminary unit cell determination by using a short pre-experiment prior to full data collection. This pre- 
experiment was used to screen a large number of crystals from each crystallisation, with full data collection only run if a discrepancy was identified between the experimental unit cell parameters and those found in the CCDC. Following full data collection, ShelXL ${ }^{47}$ was used for structure solution and a leastsquares refinement was run, using the Olex2 (ref. 48) software. Temperatures down to $100 \mathrm{~K}$ were also employed to monitor the contraction of the unit cell.

Following screening by SXRD, the most crystalline components of each crystallisation were ground to a fine powder and their structure was checked by PXRD to ensure no changes had occurred, by comparing the experimental powder pattern to the pattern predicted from the crystal structure. In house PXRD was performed on a Panalytical X'Pert Pro MPD equipped with a curved Ge Johansson monochromator, giving pure $\mathrm{Cu} \mathrm{K}_{\alpha 1}(1.5406 \AA)$ radiation and a solidstate PiXcel detector. The powder was mounted on a zerobackground offcut-Si holder, spinning at $30 \mathrm{rpm}$ with a step size of $0.013^{\circ}$ and a time per step of $\sim 750 \mathrm{~s}$. Static transmission PXRD experiments were performed on a Xenocs Xeuss 2.0 SAXS diffractometer under $\mathrm{Cu} \mathrm{K}_{\alpha 1,2}$ radiation and a Pilatus $300 \mathrm{~K}$ area detector. The powders were loaded into $1.0 \mathrm{~mm}$ diameter borosilicate capillaries. High resolution PXRD patterns were collected on beamline I11 at the Diamond Light Source (DLS), UK, using a wavelength of $0.8249 \AA$ A. Powders were loaded into $0.7 \mathrm{~mm}$ diameter borosilicate capillaries, mounted on the beamline on a spinning brass holder. Diffraction patterns were recorded using both the position sensitive detector (PSD) and multi-analysing crystals (MAC). Half way through the MAC scans (20 $\mathrm{min}$ ), the position of the capillary in the beam was moved to prevent sample degradation from the beam. PSD scans $(\sim 2 \mathrm{~min})$ were recorded at the starting position on the capillary before and after the MAC scan to check for any change. A comprehensive analysis of the powder patterns was undertaken using TOPAS Academic v6, ${ }^{49}$ which was used for Le Bail ${ }^{50}$ and Rietveld ${ }^{51}$ refinements.

\section{NMR}

1D ${ }^{1} \mathrm{H}$ one-pulse, $1 \mathrm{D}{ }^{1} \mathrm{H}^{-13} \mathrm{C}$ cross-polarisation (CP) MAS and 2D ${ }^{1} \mathrm{H}_{-}{ }^{13} \mathrm{C}$ heteronuclear correlation (HETCOR) experiments were performed on a Bruker Avance III spectrometer, operating at ${ }^{1} \mathrm{H}$ and ${ }^{13} \mathrm{C}$ Larmor frequencies of $500.0 \mathrm{MHz}$ and 125.8 MHz, respectively. A $1.3 \mathrm{~mm} \mathrm{HXY}$ probe in double resonance mode and a $4 \mathrm{~mm} \mathrm{HX}$ probe was used for singlechannel ${ }^{1} \mathrm{H}$ and ${ }^{1} \mathrm{H}-{ }^{13} \mathrm{C}$ experiments, respectively. In all cases (except during CP), a ${ }^{1} \mathrm{H}$ nutation frequency of $100 \mathrm{kHz}$ was used corresponding to a ${ }^{1} \mathrm{H} 90^{\circ}$ pulse duration of $2.5 \mu \mathrm{s}$. A ${ }^{1} \mathrm{H}$ one-pulse MAS spectrum was acquired with 16 coadded transients using a recycle delay of $100 \mathrm{~s}$. A ${ }^{13} \mathrm{C}$ CP MAS spectrum was acquired with 32 coadded transients, a CP contact time of $750 \mu \mathrm{s}$ and a recycle delay of 78 s. A $2 \mathrm{D}{ }^{1} \mathrm{H}-{ }^{13} \mathrm{C}$ HETCOR spectrum was acquired with 16 transients coadded for each of $72 t_{1}$ FIDs using a recycle delay of $78 \mathrm{~s}$, a $t_{1}$ increment of $80 \mu \mathrm{s}$ and a CP contact time of $200 \mu \mathrm{s}$ (corresponding to a total experiment time of $25 \mathrm{~h}$ ). eDUMBO- $1_{22}$ (ref. 52 and 53) homonuclear decoupling was used with a $32 \mu$ s cycle, with 320 divisions of $100 \mathrm{~ns}$ each. The scaling factor was determined to be 1.8. In the HETCOR pulse sequence, the following phase cycling was employed: ${ }^{1} \mathrm{H} 90^{\circ}$ pulse $\left(90^{\circ} 270^{\circ}\right)$, ${ }^{13} \mathrm{C}$ CP contact pulse $\left(2\left\{0^{\circ}\right\} 2\left\{180^{\circ}\right\} 2\left\{90^{\circ}\right\} 2\left\{270^{\circ}\right\}\right)$, receiver $\left(0^{\circ} 180^{\circ} 180^{\circ} 0^{\circ} 90^{\circ} 270^{\circ} 270^{\circ} 90^{\circ}\right)$. For both CP MAS and HETCOR ${ }^{1} \mathrm{H}_{-}{ }^{13} \mathrm{C}$ experiments, SPINAL64 (ref. 54) ${ }^{1} \mathrm{H}$ heteronuclear decoupling was applied during the acquisition of the ${ }^{13} \mathrm{C}$ FID, with a pulse duration of $5.9 \mu$ s at a nutation frequency of $100 \mathrm{kHz}$, and a 70 to $100 \%$ ramp $^{55}$ on the ${ }^{1} \mathrm{H}$ channel was used for the CP contact time with nutation frequencies of 47.5 and $60 \mathrm{kHz}$ for ${ }^{13} \mathrm{C}$ and ${ }^{1} \mathrm{H}$, respectively.

2D ${ }^{1} \mathrm{H}$ single quantum (SQ) spin-diffusion (NOESY-type), 2D ${ }^{1} \mathrm{H}$ double quantum (DQ) with one rotor period of $\mathrm{BaBa}$ recoupling ${ }^{56,57}$ and 2D ${ }^{14} \mathrm{~N}-{ }^{1} \mathrm{H} \quad \mathrm{HMQC}^{58-61}$ with $R^{3}$ recoupling ${ }^{62,63}$ experiments were performed on a Bruker Avance II+ spectrometer, operating at ${ }^{1} \mathrm{H}$ and ${ }^{14} \mathrm{~N}$ Larmor frequencies of $600.0 \mathrm{MHz}$ and $43.4 \mathrm{MHz}$, respectively, using a 1.3 mm HXY Bruker probe in double resonance mode. They each employed a rotor synchronized $t_{1}$ increment of $16.67 \mu \mathrm{s}$. A spin-diffusion spectrum was acquired with 4 coadded transients for each of $82 t_{1}$ FIDs using a recycle delay of $100 \mathrm{~s}$ and a spin-diffusion mixing time of $300 \mathrm{~ms}$. A ${ }^{1} \mathrm{H}$ DQ spectrum was acquired with 32 coadded transients for each of $224 t_{1}$ FIDs using a recycle delay of $10 \mathrm{~s}$. A HMQC spectrum was acquired with 16 coadded transients for each of $240 t_{1}$ FIDs using a recycle delay of $60 \mathrm{~s}$ and $133 \mu \mathrm{s}$ of $R^{3}$ recoupling. The total experiment times were 9, 20 and $64 \mathrm{~h}$, respectively. In $2 \mathrm{D}$ experiments, the States-TPPI method was employed for sign discrimination. ${ }^{64}$

${ }^{13} \mathrm{C}$ and ${ }^{1} \mathrm{H}$ chemical shifts are referenced with respect to tetramethylsilane (TMS) via L-alanine at natural abundance as a secondary reference $\left(1.1 \mathrm{ppm}\right.$ for the $\mathrm{CH}_{3}{ }^{1} \mathrm{H}$ resonance and $177.8 \mathrm{ppm}$ for the $\mathrm{CO}{ }^{13} \mathrm{C}$ resonance) corresponding to adamantane at $1.85 \mathrm{ppm}\left({ }^{1} \mathrm{H}\right)^{65}$ and $38.5 \mathrm{ppm}\left({ }^{13} \mathrm{C}\right) \cdot{ }^{66}{ }^{14} \mathrm{~N}$ shifts are referenced with respect to a saturated $\mathrm{NH}_{4} \mathrm{Cl}$ aqueous solution via spectra of $\mathrm{L}-\beta$-aspartyl-L-alanine at natural abundance $(-284 \mathrm{ppm}$ for the lower $\mathrm{NH}$ resonance at a Larmor frequency of $43.4 \mathrm{MHz}$ ) corresponding to liquid $\mathrm{CH}_{3} \mathrm{NO}_{2}$ at 0 ppm. ${ }^{60,67}{ }^{1} \mathrm{H},{ }^{13} \mathrm{C}$ and ${ }^{14} \mathrm{~N}$ shifts can be experimentally determined to an accuracy of $\pm 0.2, \pm 0.1$ and \pm 5 ppm, respectively.

Solution-state NMR was carried out on a Bruker Avance III spectrometer operating at a ${ }^{1} \mathrm{H}$ Larmor frequency of 400.0 MHz. Samples were dissolved in DMSO- $\mathrm{d}_{6}$ at a concentration of approximately $10 \mathrm{mg} \mathrm{mL}{ }^{-1} \cdot 1 \mathrm{D}{ }^{1} \mathrm{H}$ one-pulse experiments were referenced to TMS via the residual solvent peak.

\section{Results and discussion}

\section{XRD}

Single crystals of 2,6-lutidinium hydrogen fumarate were successfully obtained by slow evaporation. Crystals exhibited a thin plate morphology and, upon closer inspection with an optical microscope, thicker regions of the specimen could be 
seen as stacks of multiple thin plates, with some evidence of intergrowths.

To ensure that each sample was homogeneous, room temperature SXRD at $293 \mathrm{~K}$ was utilised to screen each crystallisation for unit cell variations and polymorphism. Most of the crystals found to be suitable for diffraction refined to the structure, published by Pan et al. ${ }^{31}$ (CCDC ref.: MIBYEB, no.: 181445, see Fig. 1). The single exception to this is discussed below. During the crystal screening, the unit cell of 181445 was also seen in many other crystals judged unsuitable for full data collection due to poor diffraction.

For all the plate crystals analysed by SXRD, the ( $\left.\begin{array}{lll}0 & 1 & 0\end{array}\right)$ plane constituted the largest face, exhibiting least growth (Fig. S2†). This corresponds to a low drive for aligning the hydrogen-bonded fumarate chains (Fig. 1c) along the $b$ axis. Conversely, the smallest crystal face, corresponding to the most favourable growth, relates to alignment of the chain structures along the $a$ axis forming the $\left(\begin{array}{lll}1 & 0 & 0\end{array}\right)$ crystal plane. The growth of the chains themselves, that results in the stacks of lutidine molecules (Fig. 1c), is moderate.

Following grinding to a powder, room temperature PXRD patterns were run to ensure no changes had been induced during the grinding process. Fig. 2 shows the result of a Rietveld refinement against a high-resolution synchrotron scan of 2,6-lutidinium hydrogen fumarate carried out under ambient conditions with a $R_{\text {bragg }}$ of $5.59 \%$. As can be seen in Table 1 , there is good agreement between the refined unit cell (MAC $300 \mathrm{~K}$ ) and that of structure 181445 published by Pan et al., ${ }^{31}$ with only small differences in the unit cell parameters consistent with the small difference in temperature between data collections. A more detailed comparison of atomic coordinates is presented in Table S1. $\dagger$

In the Rietveld refinement all the experimental reflections (as shown by the tick marks) are replicated in the calculated pattern and their $2 \theta$ positions are in excellent agreement. Although there was some evidence of differences in peak height and shape between experiment and calculation, as seen in the difference plot in Fig. 2, this can be explained by residual preferred orientation effects. The natural plate morphology of the crystals results in strong preferred orientation effects due to the alignment of crystallites. Minimisation of this by grinding the powder more finely, to allow the collection of better PXRD data, was hindered by breakdown of the crystal structure if the sample was ground for too long (discussed below). Most powders analysed therefore still contained microcrystallites, exacerbating the preferred orientation effects. Taking these effects into account, the Rietveld refinement of the PXRD data were therefore considered sufficient

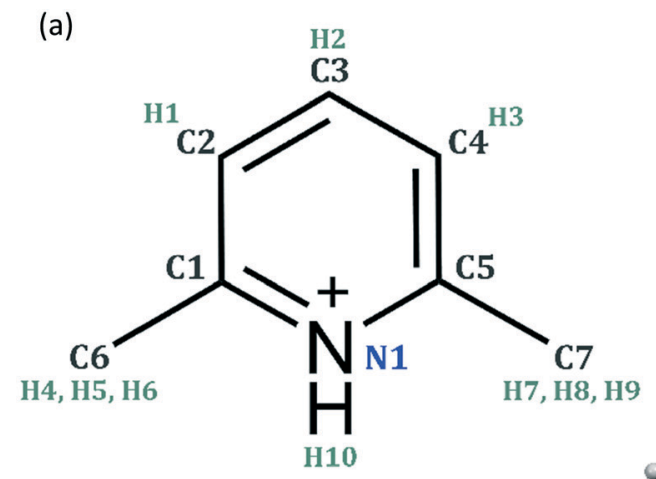

(c)

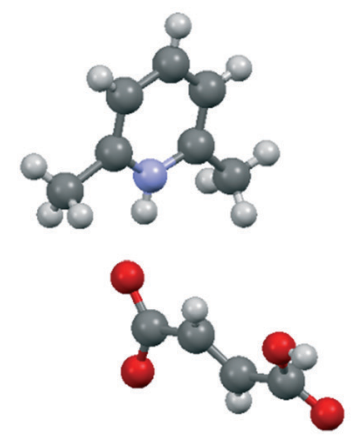

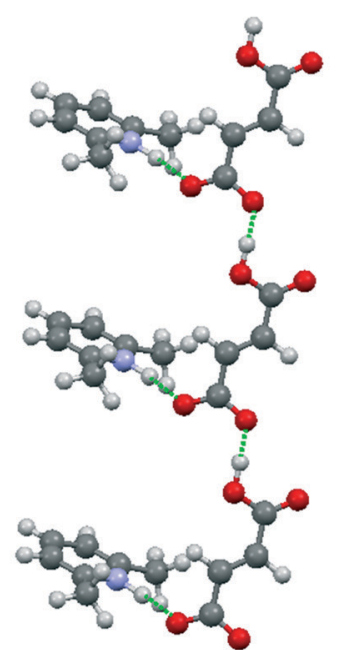

(b)

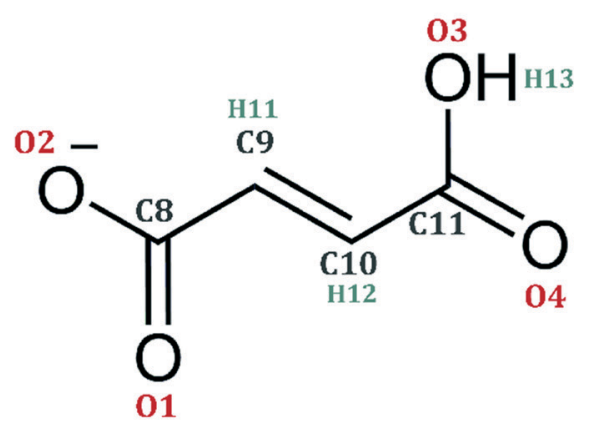

(d)

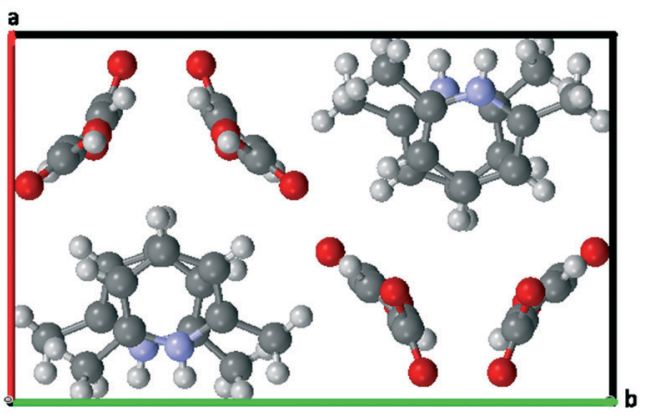

Fig. 1 Molecular structures of (a) 2,6-lutidinium and (b) hydrogen fumarate molecules with the atomic labels used in this work; (c) asymmetric unit of the DFT-optimised crystal structure of 2,6-lutidinium hydrogen fumarate (left) and stacking of the asymmetric units to form hydrogenbonded chain structures (right); (d) packing of the unit cell viewed along the $c$ axis. Carbon, oxygen, nitrogen and hydrogen atoms are shown as grey, red, purple/blue and white circles. 


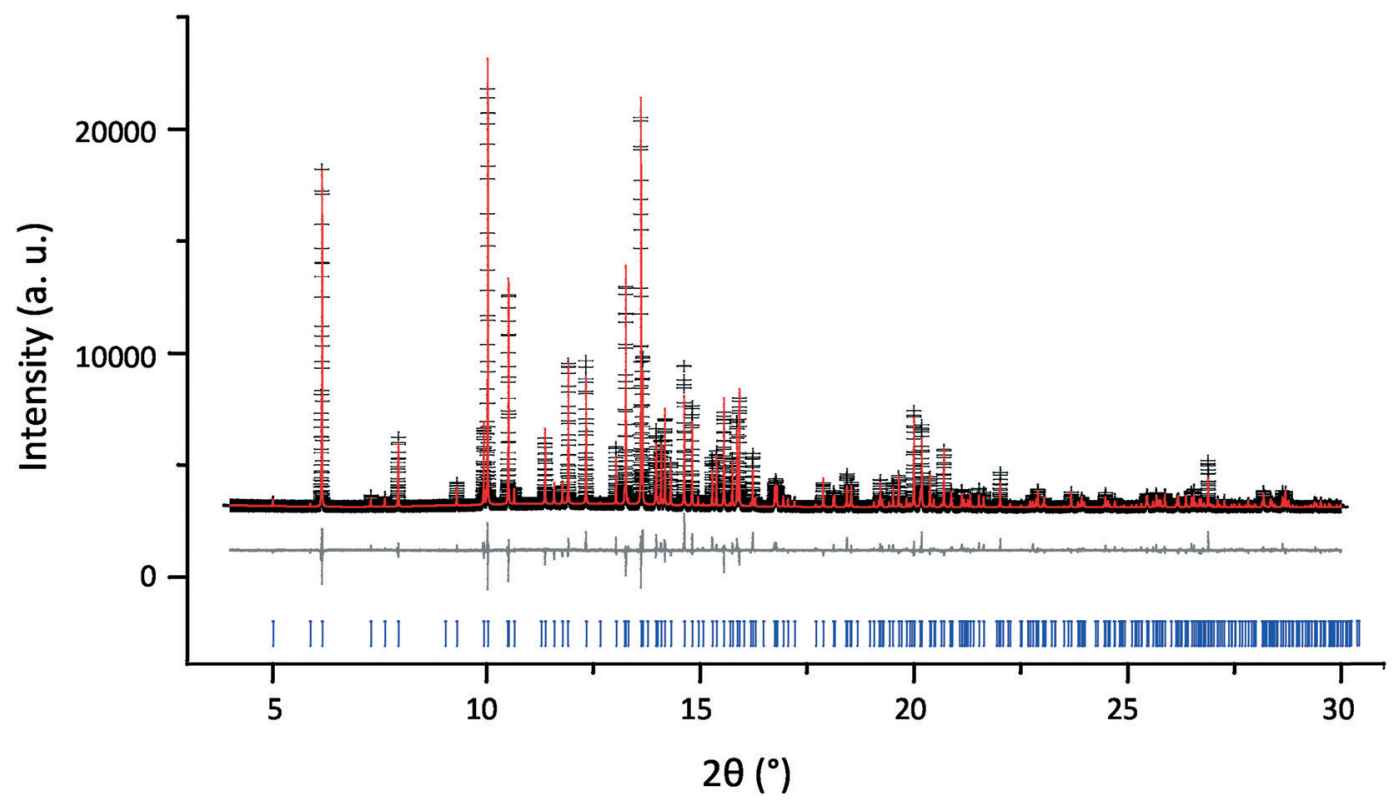

Fig. 2 Final Rietveld fit for 2,6-lutidinium hydrogen fumarate at $300 \mathrm{~K}, \lambda=0.8249 \AA$, showing the experimental (black crosses), calculated (red upper line) and difference (grey lower line) PXRD profiles. Tick marks (bottom) indicate allowed peak positions. For refinement parameters, see Tables 1, S1 and S2.†

Table 1 Comparison of unit cell parameters for 2,6-lutidinium hydrogen fumarate structure, determined at low and room temperature by both XRD and subsequent DFT geometry optimisation allowing the unit cell to vary

\begin{tabular}{lllllll}
\hline & $a(\AA)$ & $b(\AA)$ & $c(\AA)$ & $\beta\left({ }^{\circ}\right)$ & \left.${\text { Volume }\left(\AA^{3}\right)}^{\text {Energy }^{f}(\mathrm{~kJ} \mathrm{~mol}}{ }^{-1}\right)$ \\
\hline $181445^{a}(292 \mathrm{~K})$ & $9.898(2)$ & $15.347(2)$ & $7.4970(10)$ & $107.810(10)$ & $1084.3(3)$ & - \\
$\operatorname{MAC}^{b, c}(300 \mathrm{~K})$ & $9.906752(18)$ & $15.35923(3)$ & $7.501959(12)$ & $107.78973(12)$ & $1086.917(4)$ & - \\
$\operatorname{MAC}^{d}(100 \mathrm{~K})$ & $9.83096(4)$ & $15.16926(8)$ & $7.48196(3)$ & $108.8946(3)$ & $1055.651(9)$ & - \\
DFT 181445 & 9.8382 & 15.3210 & 7.4735 & 108.477 & 1068.42 & 0.9 \\
$1876100^{e}(293 \mathrm{~K})$ & $9.8451(3)$ & $15.1918(4)$ & $7.4842(2)$ & $108.573(3)$ & $1061.07(5)$ & - \\
DFT 1876100 & 9.8364 & 15.2651 & 7.4771 & 108.936 & 1061.96 & 0.0
\end{tabular}

${ }^{a}$ Structure determined by Pan et al. ${ }^{31}$ (CCDC ref.: MIBYEB, 181445), $R_{1}[I>2 \sigma(I)]=4.05 \% .{ }^{b}$ Multi-analysing crystals, high resolution synchrotron scan. ${ }^{c} R_{\text {bragg }}=5.59 \% .{ }^{d} R_{\text {bragg }}=4.7 \%$. ${ }^{e}$ Structure determined in this study, $R_{1}[I>2 \sigma(I)]=3.73 \%$. ${ }^{f}$ Relative to the structure of lowest energy (DFT 1876100). Note that the stated values correspond to a DFT geometry optimisation in CASTEP allowing atom positions and unit cell parameters to vary. For a geometry optimisation with fixed unit cells, the DFT 181445 structure has a lower energy by 4.1 kJ mol ${ }^{-1}$.

to confirm that no structural change had occurred on grinding and the published structure of 2,6-lutidinium hydrogen fumarate is a suitable model.

\section{NMR}

Fig. 3a and b presents ${ }^{1} \mathrm{H}$ one-pulse MAS and ${ }^{1} \mathrm{H}-{ }^{13} \mathrm{C}$ CP MAS NMR spectra of 2,6-lutidinium hydrogen fumarate together with stick spectra that represent the ${ }^{1} \mathrm{H}$ and ${ }^{13} \mathrm{C}$ chemical shifts calculated using the GIPAW method for the geometry optimised crystal structure (see Table $\mathrm{S} 6 \dagger$ for full listing). Generally, the level of agreement between experiment and calculation was within the established discrepancy of such calculations of $1 \%$ of the chemical shift range. ${ }^{9,27,68-70}$ The broad peak at $5-9 \mathrm{ppm}$ in the ${ }^{1} \mathrm{H}$ MAS NMR spectrum (Fig. 3a) is in agreement with GIPAW calculation. The peak corresponds to $\mathrm{CH}$ protons from both the aromatic ring and the fumarate carbon-carbon double bond backbone. There is a distinct shoulder at $6.3 \mathrm{ppm}$, as expected for $\mathrm{H} 1\left(\delta_{\text {iso }}^{\text {calc }}=6.3\right.$ ppm), the $\mathrm{CH}$ proton with the lowest calculated chemical shift, and a second shoulder at $7.9 \mathrm{ppm}$, corresponding to $\mathrm{H} 3$ and $\mathrm{H} 11$ ( $\delta_{\text {iso }}^{\text {calc }}=7.9 \mathrm{ppm}$ and $\delta_{\text {iso }}^{\text {calc }}=8.0 \mathrm{ppm}$, respectively). The single methyl (Me) peak in both experiment and calculation shows the similarity in the local environments of the two Me groups due to the symmetry of the 2,6-lutidinium molecule and its interaction with the fumarate molecule. The only discrepancy between experiment and calculation is the occurrence of two distinct peaks at high chemical shift rather than one, as discussed below.

In the ${ }^{1} \mathrm{H}^{13} \mathrm{C}$ CP MAS NMR spectrum (Fig. 3b), there is also good agreement between experimental and GIPAW calculated chemical shifts, with only small discrepancies. One of the most noticeable differences is the clear separation of C3 and C9 resonances, which are calculated as being only 0.5 

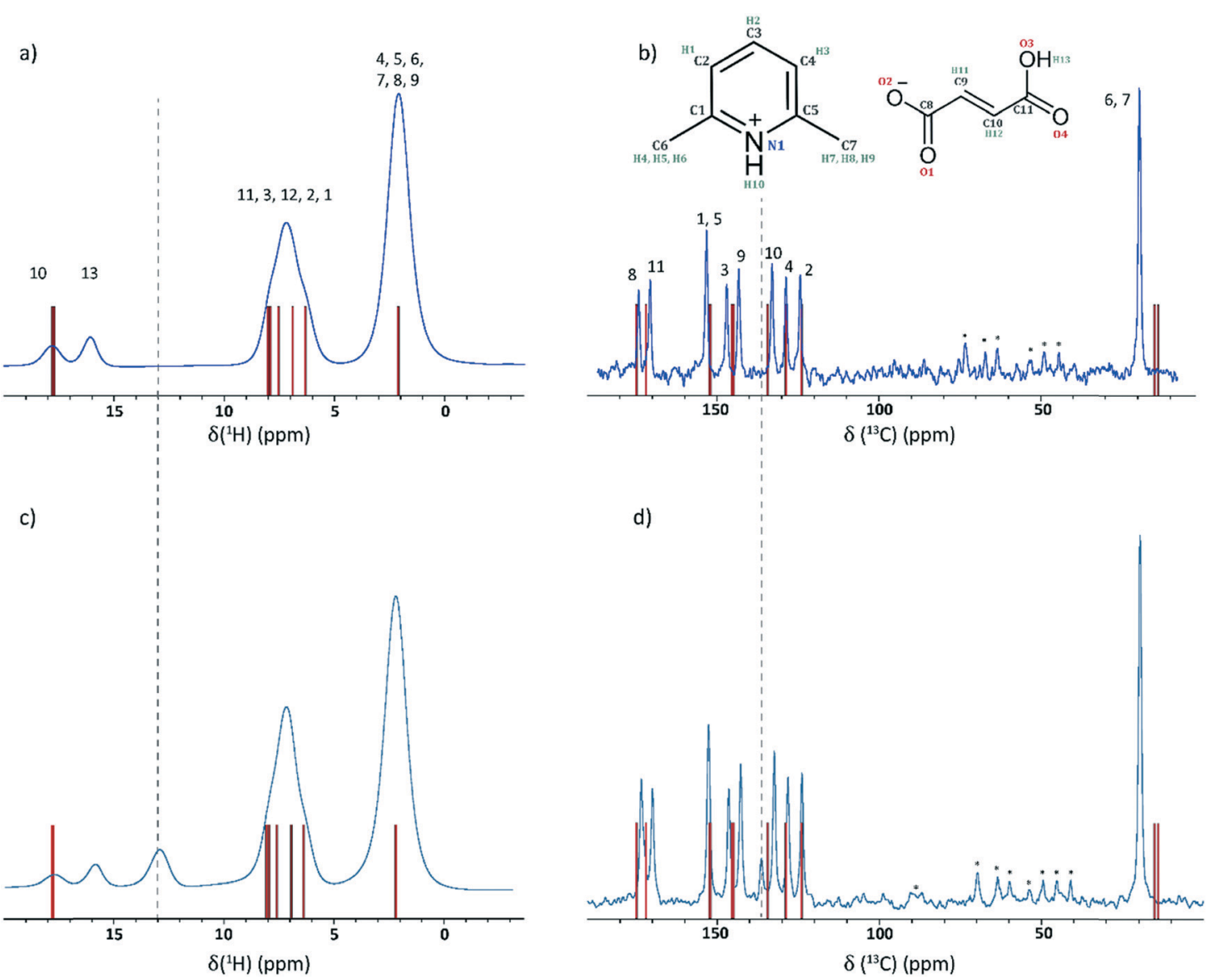

Fig. 3 (a and c) ${ }^{1} \mathrm{H}(600 \mathrm{MHz})$ one-pulse MAS $(60 \mathrm{kHz})$ NMR spectra and (b and d) ${ }^{1} \mathrm{H}(500 \mathrm{MHz})-{ }^{13} \mathrm{C}$ CP MAS (12.5 kHz) NMR spectra of 2,6lutidinium hydrogen fumarate with stick spectra corresponding to GIPAW calculated chemical shifts shown as vertical bars (red). Spectra obtained initially for the pure crystalline powder are shown at the top ( $a$ and $b$ ) while spectra obtained later after the formation of fumaric acid (see discussion in text) are shown below (c and d). The positions of the anomalous peaks that developed over time are indicated by vertical dashed lines. Asterisks denote spinning sidebands.

ppm apart (145.8 and 145.3 ppm, respectively). By comparison, two peaks are evident in the experimental spectrum, at 142.7 and $146.4 \mathrm{ppm}$. Owing to their closeness in the calculated values, it was unclear how they should be assigned on the basis of a $1 \mathrm{D}$ spectrum alone.

A 2D ${ }^{1} \mathrm{H}_{-}{ }^{13} \mathrm{C}$ HETCOR MAS NMR spectrum of 2,6lutidinium hydrogen fumarate, whereby $\mathrm{CP}$ was used to transfer magnetisation via through space dipolar couplings, is shown in Fig. 4. This was recorded using a CP contact time of $200 \mu \mathrm{s}$, such that cross peaks for longer-range $\mathrm{C}^{\cdots} \mathrm{H}$ proximities are apparent as well as direct one-bond $\mathrm{C}-\mathrm{H}$ connectivities. The ${ }^{1} \mathrm{H}-{ }^{13} \mathrm{C}$ HETCOR spectrum is shown together with crosses that represent the GIPAW calculated chemical shifts for the $\mathrm{C}-\mathrm{H}$ dipolar correlations up to $2.8 \AA$ (see Table $\mathrm{S} 3 \dagger)$. This allows an upper distance to be assigned to the observed experimental correlations by comparison to the interatomic distances extracted from the 2,6-lutidinium hydrogen fumarate crystal structure. For the zoomed region in the inset of Fig. 4, crosses for GIPAW calculated chemical shifts correspond to the directly bonded $\mathrm{CH}$ moieties $(\sim 1.1 \AA)$. The $2 \mathrm{D}$ correlation peaks show good agreement between experiment and GIPAW calculation, with only very few of the expected peaks missing, all of which are at a separation of more than $2.2 \AA$ in the 2,6-lutidinium hydrogen fumarate crystal structure. For example, no experimental cross peak is seen for the correlations of $\mathrm{C} 8$ with either $\mathrm{H} 13$ or $\mathrm{H} 10$, which correspond to distances of 2.38 and $2.53 \AA$, respectively.

The small difference in experimental correlations apparent in the zoomed in region in Fig. 4 supports assigning C3 to the ${ }^{13} \mathrm{C}$ resonance at $146.4 \mathrm{ppm}$, the higher chemical shift as per the GIPAW calculation, as its cross peak corresponds to a slightly lower proton chemical shift value than that of the resonance at $\mathbf{1 4 2 . 7} \mathrm{ppm}$. As can be seen from the GIPAW calculated chemical shifts for the directly bonded $\mathrm{C}-\mathrm{H}$ moieties, this is expected as C3 $\left(\delta_{\text {iso }}^{\exp }=146.4 \mathrm{ppm}\right)$ is directly bonded to $\mathrm{H} 2\left(\delta_{\text {iso }}^{\text {calc }}=6.9 \mathrm{ppm}\right)$ and $\mathrm{C} 9\left(\delta_{\text {iso }}^{\exp }=142.7 \mathrm{ppm}\right)$ is directly bonded to $\mathrm{H} 11\left(\delta_{\text {iso }}^{\text {calc }}=8.0 \mathrm{ppm}\right)$. C3 also has a proximity of $2.17 \AA$ to $\mathrm{H} 1$ (the lowest of the $\mathrm{CH}$ proton resonances, as stated above) as well as its directly bonded H2. C9 does not share this correlation to $\mathrm{H} 1$ so its cross peak with the $\mathrm{CH}$ region is expected to be at a higher ${ }^{1} \mathrm{H}$ chemical shift, as observed. The discrepancy between experiment and GIPAW calculation for these ${ }^{13} \mathrm{C}$ chemical shifts is -2.6 and $0.6 \mathrm{ppm}$ for $\mathrm{C} 9$ and $\mathrm{C} 3$, respectively. For $\mathrm{C} 3$, this is well 


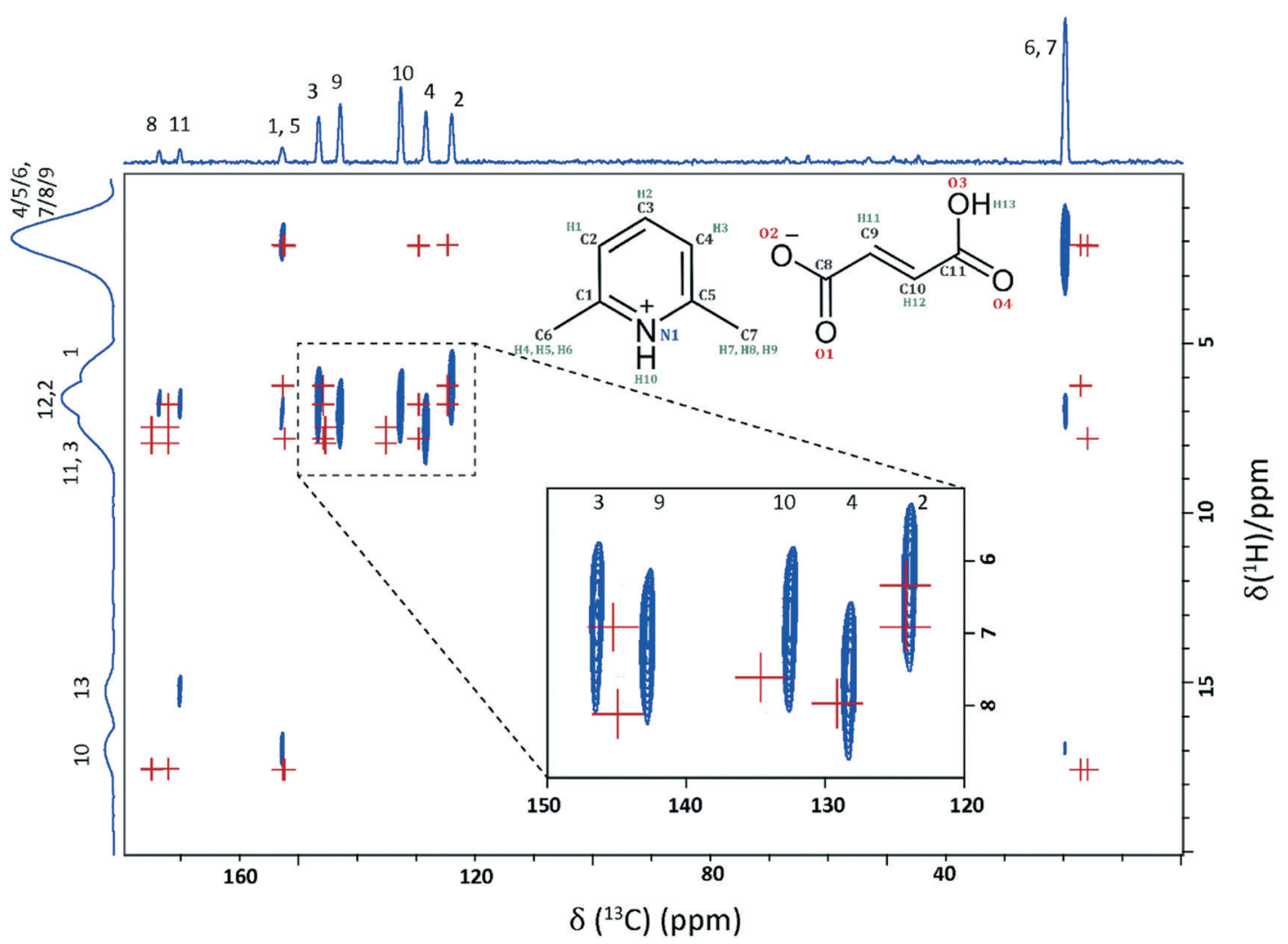

Fig. $4 \mathrm{~A}{ }^{1} \mathrm{H}(500 \mathrm{MHz})-{ }^{13} \mathrm{C} \mathrm{CP}(200 \mu \mathrm{s})$ HETCOR MAS $(12.5 \mathrm{kHz})$ NMR spectrum of 2,6-lutidinium hydrogen fumarate with calculated (GIPAW) chemical shifts shown as red crosses, for $\mathrm{CH}$ proximities out to $2.8 \AA$ and for directly bonded $\mathrm{CH}$ connectivities $(\sim 1.1 \AA \AA)$ in the zoomed-in region shown as an inset. Proximities for the quaternary carbons are listed in Table S3. $\dagger$ The base contour level is at $7.5 \%$ of the maximum peak height.

within the established discrepancy compared to experiment for such calculations of $1 \%$ of the chemical shift range $(\sim 2$ ppm for ${ }^{13} \mathrm{C}$ chemical shifts) although, with a difference of $-2.6 \mathrm{ppm}$, the discrepancy for $\mathrm{C} 9$ is slightly larger than would be expected. The only peaks that fall well outside this usual discrepancy range are the ${ }^{13} \mathrm{C}$ peaks for the Me groups, which fall $\sim 5 \mathrm{ppm}$ higher than calculated. This is a consequence of the known deviation from negative one in the gradient of a plot of experimental chemical shift against calculated chemical shielding (see, e.g., Fig. $4 \mathrm{~b}$ in ref. 40 ) $;^{71}$ an alternative approach would be to use different reference shieldings for different parts of the spectrum. ${ }^{70}$

As noted above, two peaks are observed above $10 \mathrm{ppm}$ in the ${ }^{1} \mathrm{H}$ MAS NMR spectrum (Fig. 3a) whereas, as can be seen from the stick spectra, the GIPAW calculated chemical shifts predict that both $\mathrm{H} 13$ and $\mathrm{H} 10$ (the $\mathrm{OH}$ and $\mathrm{NH}$ protons, respectively) are at the same value of $17.7 \mathrm{ppm}$. In the 2D ${ }^{1} \mathrm{H}^{-13} \mathrm{C}$ HETCOR spectrum, the absence of cross peaks between the $17.7 \mathrm{ppm}$ proton environment and $\mathrm{C} 11\left(\delta_{\mathrm{iso}}^{\exp }=\right.$ $169.9 \mathrm{ppm}$ ) suggests that $\mathrm{H} 13$ resonates at a lower ppm value compared with calculation and can be assigned to the peak at $15.7 \mathrm{ppm}$, which correlates with C11. A $2 \mathrm{D}{ }^{14} \mathrm{~N}-{ }^{1} \mathrm{H}$ HMQC spectrum, as shown and discussed later, is also in good agreement with calculation. A single $\mathrm{N}$ environment correlates with the highest proton peak $\left(\delta_{\text {iso }}^{\text {exp }}=17.7 \mathrm{ppm}\right)$, assigned as $\mathrm{H} 10$, whereby the low ${ }^{14} \mathrm{~N}$ shift, $-102 \mathrm{ppm}$, also indicates that proton transfer to the $\mathrm{N}$ has occurred and the structure is sustained by an ionic salt interaction due to its excellent agreement with the calculated ${ }^{14} \mathrm{~N}$ shift $\left(\delta^{\text {calc }}=-102.2 \mathrm{ppm}\right)$.

In the 2D DQ-SQ ${ }^{1} \mathrm{H}^{-1} \mathrm{H}$ MAS NMR spectrum presented in Fig. 5, cross peaks occur in the DQ dimension at the sum of the two SQ resonances for protons close in space (generally accepted as up to a distance of $3.5 \AA$ A). ${ }^{30}$ Table 2 lists the $\mathrm{H}^{\cdots} \mathrm{H}$ proximities under $3.5 \AA$ for the $\mathrm{NH}\left(\mathrm{H} 10, \delta_{\text {iso }}^{\exp }=17.7 \mathrm{ppm}\right)$ and $\mathrm{OH}\left(\mathrm{H} 13, \delta_{\mathrm{iso}}^{\exp }=15.8 \mathrm{ppm}\right)$ protons of 2,6-lutidinium hydrogen fumarate in the DFT geometry optimised structure. The closest proximities of the $\mathrm{OH}$ and $\mathrm{NH}$ protons are to the $\mathrm{CH}_{3}$ groups, giving peaks at $\delta_{\mathrm{DQ}}=2.1+15.8=17.9 \mathrm{ppm}$ and $\delta_{\mathrm{DQ}}=$ $2.1+17.7=19.8 \mathrm{ppm}$, respectively. The next closest proximity to the $\mathrm{NH}, \mathrm{H} 10$, is to $\mathrm{H} 11$, which also falls within $3.5 \AA$ of the $\mathrm{OH}, \mathrm{H} 13$ (see Table 2), corresponding to cross peaks at $\delta_{\mathrm{DQ}}=$ $15.8+7.9=23.7 \mathrm{ppm}(\mathrm{H} 13-\mathrm{H} 11)$ and $\delta_{\mathrm{DQ}}=17.7+7.9=25.4$ ppm (H10-H11). Unlike H10, H13 has a sufficiently close proximity to both $\mathrm{H} 2$ and $\mathrm{H} 3$ such that cross peaks are also observed at $\delta_{\mathrm{DQ}}=15.8+7.0=22.8 \mathrm{ppm}(\mathrm{H} 13-\mathrm{H} 2)$ as well as at $\delta_{\mathrm{DQ}}=15.8+7.9=23.7 \mathrm{ppm}(\mathrm{H} 13-\mathrm{H} 3)$.

\section{GIPAW calculations of NMR chemical shifts for isolated molecules}

A comparison of the chemical shifts calculated for the full crystal structure of 2,6-lutidinium hydrogen fumarate to those 


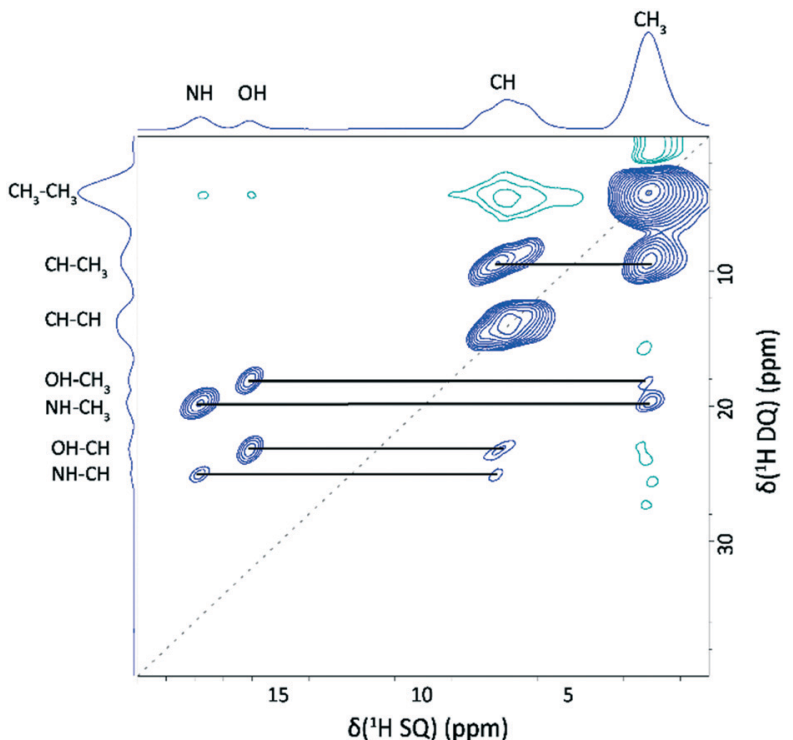

Fig. $5 \mathrm{~A}{ }^{1} \mathrm{H}(600 \mathrm{MHz})$ DQ MAS NMR spectrum of 2,6-lutidinium hydrogen fumarate recorded with one rotor period of $\mathrm{BaBa}$ recoupling. The base contour level is at $3.3 \%$ of the maximum peak height. Blue and green contours correspond to positive and negative intensity respectively. DQ/SQ correlations for the $\mathrm{NH}(\mathrm{H} 10)$ and $\mathrm{OH}$ (H13) resonances are listed in Table 2. The dashed diagonal line indicates the $\delta_{\mathrm{DQ}}=2 \delta_{\mathrm{SQ}}$ diagonal, while horizontal lines indicate a $\mathrm{DQ}$ peak at the sum of the two $S Q$ peaks for dipolar coupled unlike protons.

calculated for individual isolated molecules, as extracted from the geometry optimised crystal structure, can provide additional insight into the crystal packing. ${ }^{27,28,45,72-74}$ The difference between the crystal and isolated molecule chemical shifts (Table 3 ) indicates the presence of intermolecular interactions, with changes of more than 1 ppm being considered significant. Positive values of $\Delta \delta_{\text {Crystal-Molecule }}$ are attributed to the presence of hydrogen bonding, while negative values arise due to ring currents from $\mathrm{C}-\mathrm{H} \cdots \pi$ interactions. $^{27,72,75,76}$
Table 3 A comparison of GIPAW calculated ${ }^{1} \mathrm{H}$ shifts (in ppm) for the full crystal structure of 2,6-lutidinium hydrogen fumarate and for isolated molecules extracted from the crystal structure

\begin{tabular}{lrrrr}
\hline Atom & $\delta_{\text {Expt }}$ & $\delta_{\text {Crystal }}$ & $\delta_{\text {Molecule }}$ & $\Delta \delta_{\text {Crystal-Molecule }}$ \\
\hline H13 & 15.8 & 17.7 & 6.4 & 11.3 \\
H10 & 17.7 & 17.7 & 10.5 & 7.1 \\
H12 & 7.0 & 7.5 & 6.1 & 1.4 \\
H11 & 7.9 & 8.0 & 6.8 & 1.2 \\
H3 & 7.9 & 7.9 & 7.3 & 0.6 \\
H4/H5/H6 & 2.1 & 2.1 & 2.4 & -0.3 \\
H7/H8/H9 & 2.1 & 2.1 & 2.4 & -0.3 \\
H1 & 6.3 & 6.3 & 7.3 & -1.0 \\
H2 & 7.0 & 6.9 & 7.9 & -1.0 \\
\end{tabular}

Isolated molecule calculations were performed on CCDC 181445 following geometry optimisation. In these calculations, $\delta_{\text {iso }}^{\text {calc }}$ of the $\mathrm{OH}$ and $\mathrm{NH}$ (H13 and $\mathrm{H} 10$, respectively) are significantly higher for the crystal structure than for the isolated molecules, with both being calculated at $17.7 \mathrm{ppm}$ in the crystal rather than 6.4 and $10.5 \mathrm{ppm}$, respectively, for the isolated molecules. The hydroxyl H13 shows the largest change in chemical shift between the crystal structure and isolated molecule calculations, corresponding to the strong hydrogen bonding between adjacent hydrogen fumarate molecules to form the chains of asymmetric units seen in the geometry optimised 181445 structure (see Fig. 1; the $\mathrm{O} \cdots \mathrm{O}$ and $\mathrm{O} \cdots \mathrm{H}$ distances are 2.54 and $1.48 \AA$, respectively, with a $175^{\circ}$ $\mathrm{OHO}$ angle). The $\mathrm{NH}$ (H10) also shows evidence in isolated molecule calculations of a strong $\mathrm{H}$ bond to $\mathrm{O} 2$ as expected (the $\mathrm{N} \cdots \mathrm{O}$ and $\mathrm{O} \cdots \mathrm{H}$ distances are 2.64 and $1.55 \AA$, respectively, with a $169^{\circ}$ NHO angle), with the smaller $\Delta \delta_{\text {Crystal-Molecule }}$ corresponding to the slightly larger distance and an angle further from the ideal $180^{\circ}$ compared to the case for $\mathrm{H} 13$. A further difference is that $\mathrm{H} 10$ corresponds to a charged $\mathrm{NH}^{+}$moiety while $\mathrm{H} 13$ is in a neutral COOH group. Two $\mathrm{CH}$ protons, $\mathrm{H} 11$ and $\mathrm{H} 12$, also show some indication of a weak hydrogen bonding interaction ${ }^{28,75}$ as they exhibit a

Table $2 \mathrm{H}-\mathrm{H}$ proximities $(<3.5 \AA \AA)$ and corresponding ${ }^{1} \mathrm{H}$ DQ chemical shifts for the $\mathrm{NH}$ and $\mathrm{OH}$ protons in 2,6-lutidinium hydrogen fumarate

\begin{tabular}{|c|c|c|c|c|c|}
\hline Proton 1 & $\delta_{\text {iso }}^{\exp } \mathrm{SQ} 1(\mathrm{ppm})$ & Proton 2 & $\delta_{\text {iso }}^{\exp } \mathrm{SQ} 2(\mathrm{ppm})$ & $\delta_{\text {iso }}^{\exp } \mathrm{DQ}(\mathrm{ppm})$ & $\operatorname{Separation}^{a}(\AA)$ \\
\hline \multirow[t]{8}{*}{$\mathrm{H} 13(\mathrm{OH})$} & \multirow[t]{8}{*}{15.8} & $\mathrm{H} 9\left(\mathrm{CH}_{3}\right)$ & 2.1 & 17.9 & 2.52 \\
\hline & & $\mathrm{H} 4\left(\mathrm{CH}_{3}\right)$ & 2.1 & 17.9 & 2.87 \\
\hline & & $H 11(\mathrm{CH})$ & 7.9 & 23.7 & 2.88 \\
\hline & & H3 (CH) & 7.9 & 23.7 & 2.97 \\
\hline & & $\mathrm{H} 2(\mathrm{CH})$ & 7.0 & 22.8 & 3.04 \\
\hline & & $\mathrm{H} 2(\mathrm{CH})$ & 7.0 & 22.8 & 3.26 \\
\hline & & $\mathrm{H} 5\left(\mathrm{CH}_{3}\right)$ & 2.1 & 17.9 & 3.41 \\
\hline & & $\mathrm{H} 11(\mathrm{CH})$ & 7.9 & 23.7 & 3.47 \\
\hline \multirow[t]{8}{*}{$\mathrm{H} 10(\mathrm{NH})$} & \multirow[t]{8}{*}{17.7} & $\mathrm{H} 5\left(\mathrm{CH}_{3}\right)$ & 2.1 & 19.8 & 2.37 \\
\hline & & $\mathrm{H} 8\left(\mathrm{CH}_{3}\right)$ & 2.1 & 19.8 & 2.51 \\
\hline & & $H 11(\mathrm{CH})$ & 7.9 & 25.4 & 2.57 \\
\hline & & $\mathrm{H} 7\left(\mathrm{CH}_{3}\right)$ & 2.1 & 19.8 & 2.71 \\
\hline & & $\mathrm{H} 4\left(\mathrm{CH}_{3}\right)$ & 2.1 & 19.8 & 2.92 \\
\hline & & $\mathrm{H} 4\left(\mathrm{CH}_{3}\right)$ & 2.1 & 19.8 & 3.04 \\
\hline & & $H 11(\mathrm{CH})$ & 7.9 & 25.4 & 3.27 \\
\hline & & $\mathrm{H} 5\left(\mathrm{CH}_{3}\right)$ & 2.1 & 19.8 & 3.28 \\
\hline
\end{tabular}

${ }^{a} \mathrm{H}-\mathrm{H}$ distances are taken from the DFT (CASTEP) optimised structure. Intermolecular proximities are denoted using italic font. 
change in chemical shift of 1.2 and $1.4 \mathrm{ppm}$, respectively. $\mathrm{H} 11$ is weakly bonded to $\mathrm{O} 2$ in the stacked chain $(\mathrm{C} \cdots \mathrm{O}$ distance of $3.43 \AA$, $\mathrm{CH} \cdots \mathrm{O}$ distance of $2.38 \AA$ and $\mathrm{CHO}$ angle $161^{\circ}$ ) and $\mathrm{H} 12$ is weakly bonded to $\mathrm{O} 4$ in the adjacent fumarate chain $(\mathrm{C} \cdots \mathrm{O}$ distance of $3.50 \AA$, $\mathrm{CH} \cdots \mathrm{O}$ distance of 2.45 Å and CHO angle $161^{\circ}$ ).

$\mathrm{H} 1$ and $\mathrm{H} 2$ exhibit weak ring current effects (-1.0 ppm), possibly due to the stacking of the pyridine rings within the crystal structure, although it is interesting to note that this effect seems to be offset for $\mathrm{H} 3$ which instead shows a very slight positive change $(0.6 \mathrm{ppm})$. This is due to weaker effects from ring currents, as the stacking is slightly misaligned (Fig. 1d, bottom right), placing it further out from the $\pi-\pi$ stack.

\section{Skewed cell contraction}

Fig. 6 shows a Rietveld refinement against a PXRD high resolution synchrotron scan that was collected at $100 \mathrm{~K}$. As with the room temperature high resolution scan shown in Fig. 2, residual preferred orientation effects prevent accurate refinement of atomic positions, but the tick marks, corresponding to $2 \theta$ values of the reflections expected for the refined structure, are in excellent agreement with those recorded experimentally. As can be seen in Table 1, this Rietveld refinement showed a contraction accompanied by an increase in the $\beta$ angle. This effect was also observed in SXRD crystal screens conducted at a range of temperatures between $100 \mathrm{~K}$ and 300 K (Fig. S3†).

Compared to 181445, the Rietveld refinement for the 300 K PXRD pattern presented above (Fig. 2) shows a small, but similarly skewed expansion, with a marginal decrease in $\beta$ an- gle, alongside increases in cell lengths, consistent with being recorded at a slightly higher temperature than the literature structure (300 K compared to $292 \mathrm{~K}$ ). The skew in the cell, when going to low temperature during contraction, is also evident in the DFT calculations (also shown in Table 1). Geometry optimisations, performed allowing the unit cell parameters to vary, showed convergence towards the low temperature structure. As no external temperature is included in the calculations, they are effectively performed at $0 \mathrm{~K}$, so it is unsurprising they would exhibit such a tendency.

During the room temperature crystal SXRD screening to check each crystallisation for variations or new polymorphs, one crystal was identified that differed slightly from the previously identified structure. This newly identified structure has been deposited with the CCDC (no. 1876100) and selected crystal data are given in Table 4. Although the molecular packing of the crystal remained unchanged, with only small shifts in relative atomic positions (Fig. 7), the unit cell parameters presented in Table 1 show both a slight contraction in the unit cell lengths (the most significant being a reduction of $0.15 \AA$ on the $b$ axis) and a $0.76^{\circ}$ widening of the $\beta$ angle compared with 181445 , which was recorded at $292 \mathrm{~K}$. Intramolecular one-bond atomic distances actually increased by an average of $0.006 \AA$, with the mean $\mathrm{C}-\mathrm{C} / \mathrm{N}$ one-bond separation in the pyridine ring changing from $1.367 \AA$ in the original structure to $1.373 \AA$ in 1876100 . However, intermolecular distances between the atoms of neighbouring molecules decreased by an average of $0.03 \AA$ (where intermolecular distances up to $6 \AA$ were considered), with this value dominated by the distances in the $b$ dimension, with the $\mathrm{O} \cdots \mathrm{O}$ hydrogen bond (aligned with the $a$ dimension)

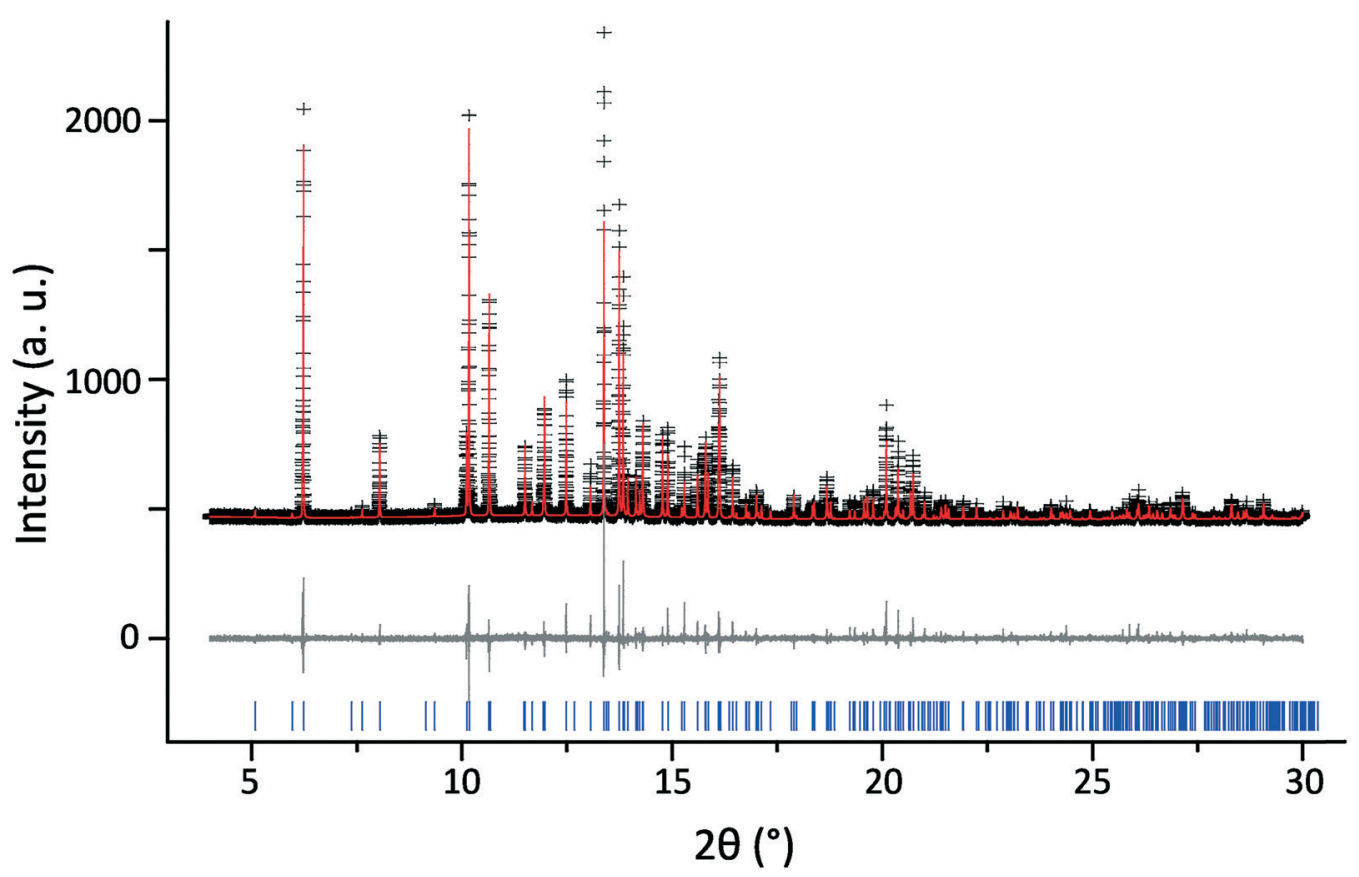

Fig. 6 Final Rietveld fit for 2,6-lutidinium hydrogen fumarate at $100 \mathrm{~K}$, showing the experimental (black crosses), calculated (red upper line) and difference (grey lower line) PXRD profiles. Tick marks indicate allowed peak positions. For refinement parameters, see Tables 1, S4 and S5. $\dagger$ 
Table 4 Selected crystal data for 1876100

\begin{tabular}{llll}
\hline Chemical formula & $\mathrm{C}_{11} \mathrm{H}_{13} \mathrm{O}_{4} \mathrm{~N}$ & Temperature $(\mathrm{K})$ & $293(2)$ \\
Formula weight & 223.22 & $\mu\left(\mathrm{mm}^{-1}\right)$ & 0.900 \\
Crystal system & Monoclinic & Independent reflections & 2076 \\
Space group & $P 2_{1} / n$ & $R_{\text {int }}$ & 0.0232 \\
$Z$ & 4 & $R_{1}[I>2 \sigma(I)]$ & 0.0317
\end{tabular}

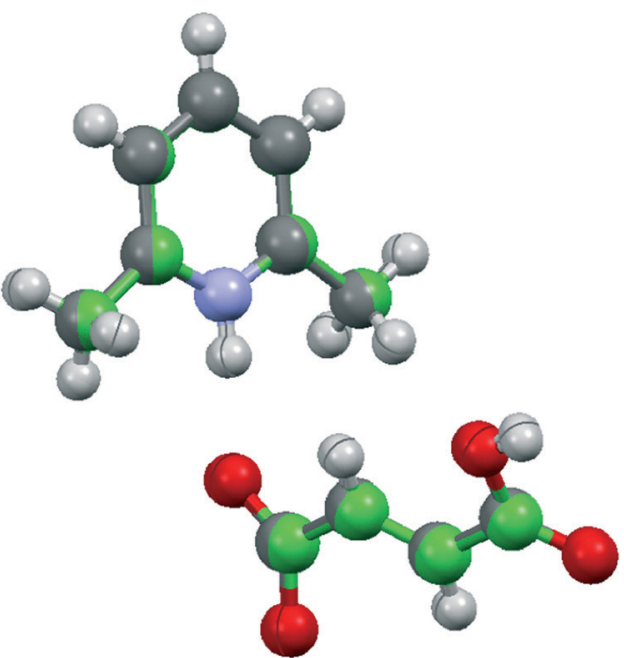

Fig. 7 Overlay of the asymmetric unit of the newly identified structure deposited to the CCDC as 1876100 (carbon atoms in green) and of the previously published structure (ref.: 181445 , carbon atoms in grey).

decreasing by $0.01 \AA$ compared to a decrease of $0.06 \AA$ for the $\mathrm{O} 3$ to $\mathrm{C} 8$ distance between neighbouring hydrogen fumarate molecules (aligned with the $b$ dimension). The form of the contraction and its corresponding skew in the $\beta$ angle are similar to that exhibited by the contraction at low temperature, although to a lesser extent.

A GIPAW calculation for 1876100 , following geometry optimisation, showed that the minimal shifts in atom position produced only small changes to the calculated chemical shifts (the largest being $0.2 \mathrm{ppm}$ for ${ }^{1} \mathrm{H}$ and $0.6 \mathrm{ppm}$ for ${ }^{13} \mathrm{C}$, with mean differences of $0.01 \mathrm{ppm}$ and $0.1 \mathrm{ppm}$, respectively, see Table S6 $\dagger$ ). These mean differences are below the experimental error and therefore make the two structures effectively indistinguishable by NMR. This in turn suggests that the skewed contraction produces no significant changes to the chemical environments for the two molecules. However, the unit cell changes, particularly the increase in $\beta$ angle, are sufficient to visibly change the $2 \theta$ positions of reflections in the simulated PXRD pattern with respect to the literature structure (Fig. S4 $\dagger$ ).

A second example of 1876100 was not identified within any of the single crystal screens, for more than 20 crystals, with all other crystals converging to the 181445 structure of 2,6-lutidinium hydrogen fumarate at room temperature. The observation that no more crystals showing this contraction were identified may be due to the minimal presence of
1876100 or a bias in which single crystals were analysed. A difference in crystal quality, exhibited either by their appearance or quality of diffraction, could create such a bias.

Extensive PXRD analysis failed to provide conclusive evidence for even a minor second structural phase within the powdered compound, suggesting that 1876100 may have been an isolated case. However, in the case of only partially ground powders (so as to as minimise break down of the cocrystal, see below discussion), some of the reflections appeared to show a splitting. Several larger crystallites were observed in static transmission PXRD of these samples, using a $2 \mathrm{D}$ detector, that may explain this. They lie slightly off the main powder ring, as predicted due to a small change in $\beta$ angle (Fig. 8), and might therefore be linked to 1876100 . As 1876100 seems to be related to the low temperature contraction, it is unclear how it existed within a room temperature SXRD screen. The energies of 181445 and 1876100 , determined by DFT (see Table 1), differed by only $0.9 \mathrm{~kJ} \mathrm{~mol}^{-1}$ after geometry optimisation (allowing both atom positions and unit cell parameters to vary).

Considering Table 1, it is notable that, for the DFT calculations, variable cell geometry optimisations that were started from both the previously published structure and 1876100 converged towards the $100 \mathrm{~K}$ structure but neither reached it,

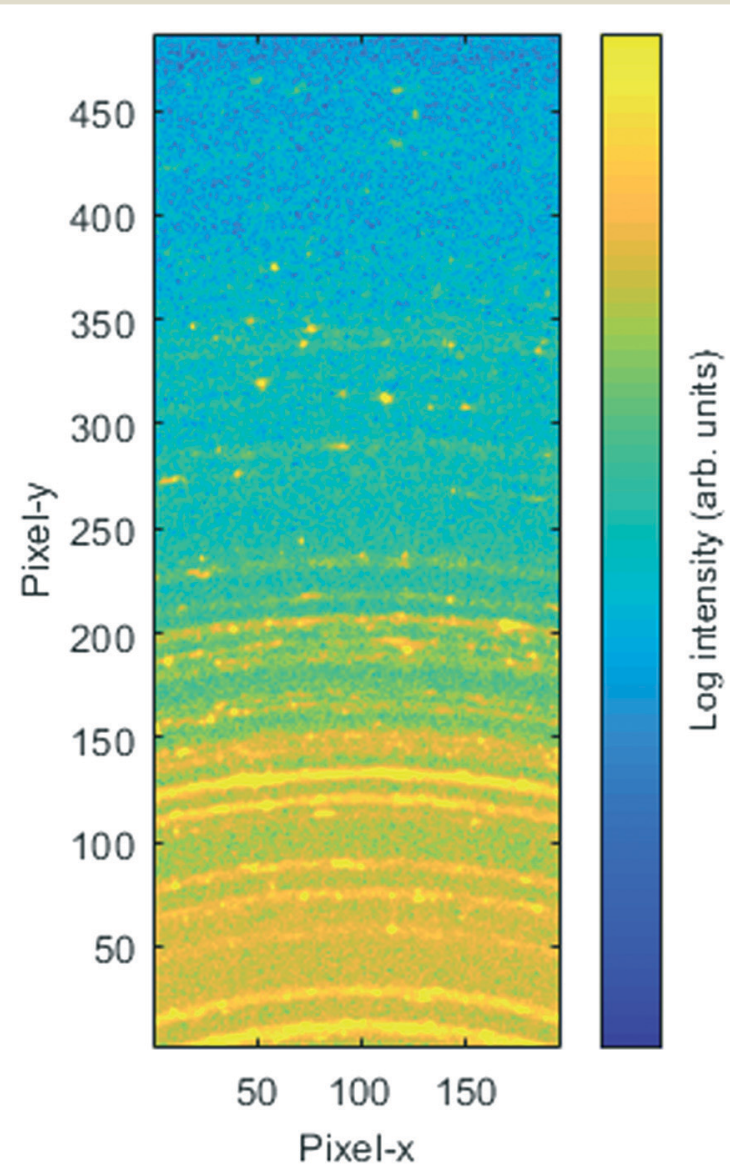

Fig. 8 Static transmission PXRD of 2,6-lutidinium hydrogen fumarate with a $2 \mathrm{D}$ detector. 
with each satisfying the convergence conditions of the DFT calculation with larger volume unit cells than that of the 100 $\mathrm{K}$ structure. This discrepancy is probably due to the limitations of the dispersion correction scheme. Although the difference between the two unit cells was smaller following variable cell geometry optimisation, the output of the calculation based on 1876100 was still slightly more contracted than that based on the original CCDC structure, 181445. It can also clearly be seen (Table 1 ) that despite effectively being at a lower temperature $(0 \mathrm{~K})$, the outputs of neither calculation exhibit as significant a contraction as is evident for the $100 \mathrm{~K}$ synchrotron case, although the optimisation of $1876100 \mathrm{did}$ produce a similar skew of the $\beta$ angle.

\section{Formation of fumaric acid}

Samples that had been stored for more than a week as powders rather than single crystals showed additional peaks in the ${ }^{1} \mathrm{H}$ MAS and ${ }^{1} \mathrm{H}^{13} \mathrm{C}$ CP MAS NMR spectra, as shown in Fig. $3 \mathrm{c}$ and $\mathrm{d}$. The high chemical shift of the new ${ }^{1} \mathrm{H}$ peak, $12.9 \mathrm{ppm}$, is indicative of strong hydrogen bonding. A $2 \mathrm{D}$ ${ }^{14} \mathrm{~N}-{ }^{1} \mathrm{H}$ HMQC MAS NMR spectrum showed only the peak identified during the initial analysis (Fig. 9b), confirming the presence of a single $\mathrm{N}$ environment and therefore indicating that the new ${ }^{1} \mathrm{H}$ resonance likely corresponds to an $\mathrm{OH}$ group. A 2D ${ }^{1} \mathrm{H}^{13}{ }^{13} \mathrm{C}$ HETCOR MAS NMR spectrum (Fig. S5 $\dagger$ ) did not show the additional ${ }^{1} \mathrm{H}$ peak, further supporting the assignment as an $\mathrm{OH}$. The extra ${ }^{13} \mathrm{C}$ peak that had been identified in the ${ }^{1} \mathrm{H}-{ }^{13} \mathrm{C}$ CP MAS spectrum did correlate with protons in the $\mathrm{CH}$ region, however, suggesting a second new ${ }^{1} \mathrm{H}$ resonance lies under the $\mathrm{CH}$ region. The closeness in chemical shift of this new ${ }^{13} \mathrm{C}$ resonance to that of $\mathrm{C} 10$ hinted that it may correspond to a carbon in the fumarate backbone.

A 2D ${ }^{1} \mathrm{H}^{1}{ }^{1} \mathrm{H}$ DQ-SQ MAS NMR spectrum (Fig. 9a) shows that two cross peaks are observed for the newly appearing proton resonance (labelled as $\mathrm{P} 2$ ). These correspond to an auto-correlation $\left(\delta_{\mathrm{DQ}}=13.0+13.0=26.0 \mathrm{ppm}\right)$ and a correlation with the $\mathrm{CH}$ region $\left(\delta_{\mathrm{DQ}}=13.0+7.0=20.0 \mathrm{ppm}\right)$, corresponding to the same ${ }^{1} \mathrm{H}$ chemical shift as $\mathrm{H} 11$ or H12. A 2D SQ ${ }^{1} \mathrm{H}^{-}{ }^{1} \mathrm{H}$ NOESY spectrum (Fig. 9c) clearly shows the presence of two distinct phases. A mixing time of $300 \mathrm{~ms}$ was used to allow spin diffusion throughout the entire system which should result in cross peaks between all protons within the same phase. ${ }^{77,78}$ The absence of cross peaks for the $12.9 \mathrm{ppm}$ resonance with the $\mathrm{Me}$ and $\mathrm{NH}$ protons in either of the ${ }^{1} \mathrm{H}-{ }^{1} \mathrm{H}$ 2D correlation experiments, coupled with the proximity to the $\mathrm{CH}$ region shown in the DQ experiment, suggests that the secondary phase does not contain 2,6-lutidine and may correspond to crystalline fumaric acid. This is supported by the correlation between the anomalous $\mathrm{C}$ peak with the $\mathrm{CH}$ region in the ${ }^{1} \mathrm{H}^{1}{ }^{13} \mathrm{C}$ HETCOR spectrum (Fig. S5 $\dagger$ ), and the $\mathrm{OH}^{1} \mathrm{H}$ chemical shift of $13 \mathrm{ppm}$ (ref. 79) and the two ${ }^{13} \mathrm{C}$ chemical shifts of $136.3 \mathrm{ppm}$ and $172.3 \mathrm{ppm}$ (ref. 80) reported in the literature for fumaric acid, with the higher resonance lying beneath the existing C8 peak.

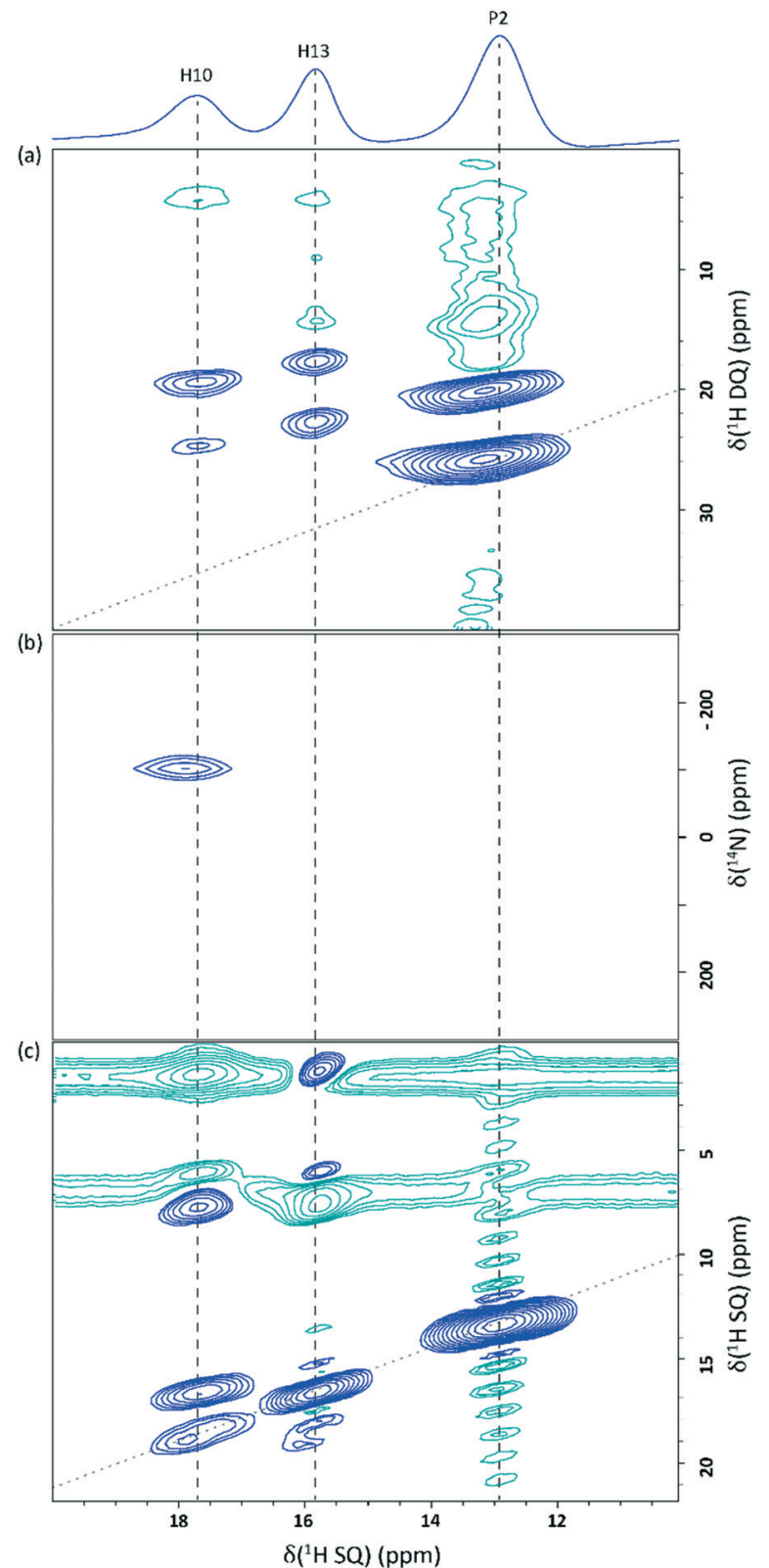

Fig. 9 2D MAS $(60 \mathrm{kHz})$ NMR spectra of 2,6-lutidinium hydrogen fumarate sample (not freshly ground into a powder) showing the 10$20 \mathrm{ppm}{ }^{1} \mathrm{H}$ region: (a) a ${ }^{1} \mathrm{H} D Q$ spectrum recorded with one rotor period of BaBa recoupling; (b) a ${ }^{14} \mathrm{~N}-{ }^{1} \mathrm{H}$ HMQC spectrum with 8 rotor periods of $R^{3}$ recoupling; and (c) a ${ }^{1} \mathrm{H} \mathrm{SQ}$ NOESY spectrum with $t_{\text {mix }}=$ $300 \mathrm{~ms}$. All spectra were recorded at a ${ }^{1} \mathrm{H}$ Larmor frequency of 600 $\mathrm{MHz}$. Base contour levels are at $5.3 \%, 36.2 \%$ and $2.3 \%$ of the maximum peak height, respectively. Blue and green contours correspond to positive and negative intensity, respectively. The negative intensities seen at the $\mathrm{CH}_{3}$ and $\mathrm{CH} F_{1}$ (vertical axis) $\mathrm{SQ}$ frequencies in (c) are due to the much greater intensity of their auto-correlation peaks. The dashed diagonal lines in (a) and (c) indicate the (a) $\delta_{\mathrm{DQ}}=2 \delta_{\mathrm{SQ}}$ and (c) $\delta_{\mathrm{SQ}}=\delta_{\mathrm{SQ}}$ diagonals.

This conclusion is supported by the position of reflections seen in a subsequent PXRD pattern recorded with a Panalytical X'Pert Pro MPD diffractometer (Fig. 10). Samples that had been stored as powders contained reflections that 


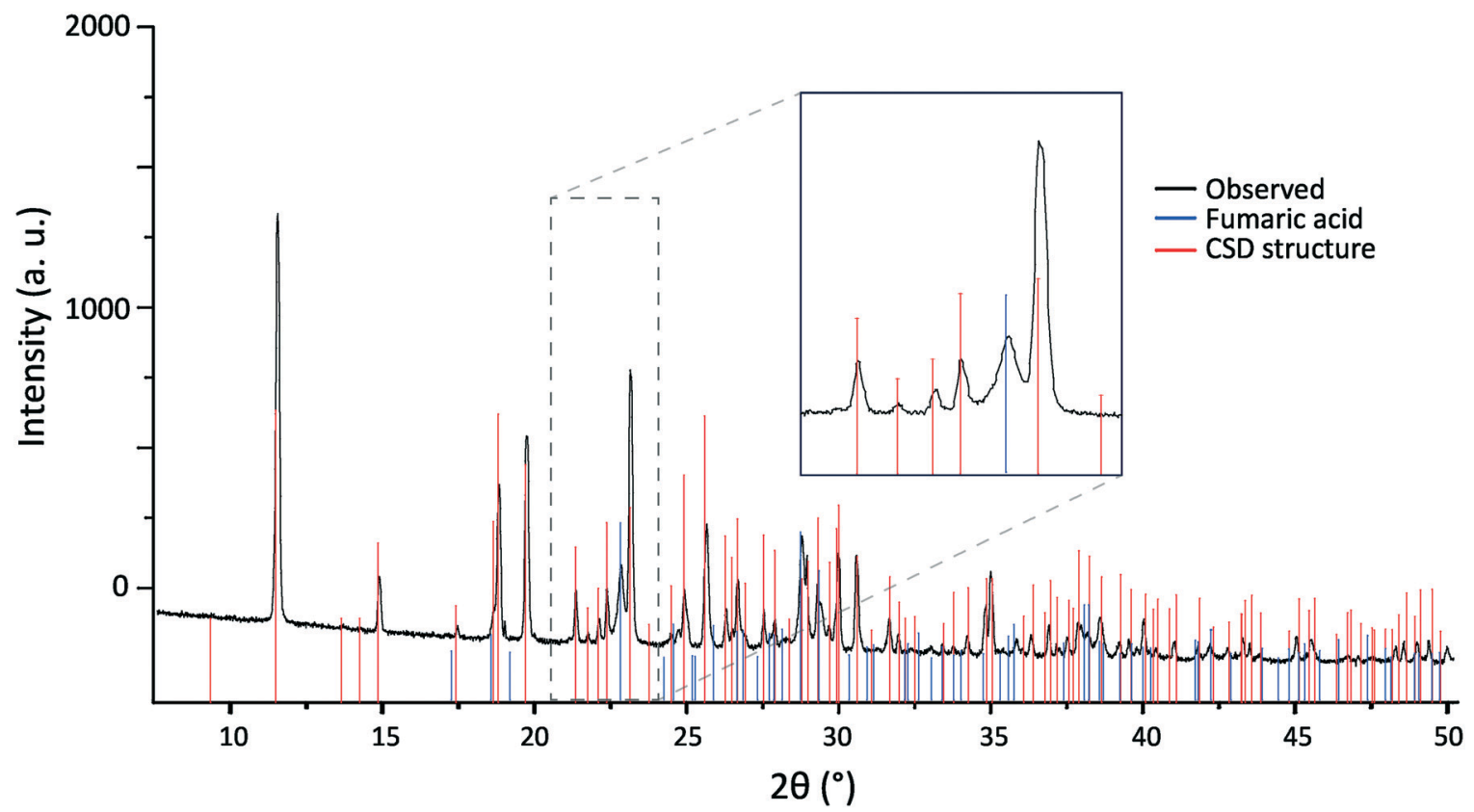

Fig. 10 PXRD pattern of 2,6-lutidinium hydrogen fumarate recorded more than a week after first being ground to powder, with tick marks representing the reflection positions simulated for CCDC structure 181445 (red) and crystalline fumaric acid (blue). The zoomed-in region (inset) shows the agreement between the additional experimental reflections and those of fumaric acid.

were not present in patterns recorded on freshly ground crystals. Although these new reflections matched well those expected for crystalline fumaric acid, ${ }^{81}$ a multiphase refinement was not possible. This was due to both the presence of splittings (possibly caused by the presence of larger crystallites of 2,6-lutidinium hydrogen fumarate with different $\beta$ angles, as shown in Fig. 8), preferred orientation effects and, crucially, significant overlap of many of the fumaric acid re- flections with those produced by 2,6-lutidinium hydrogen fumarate.

This formation of fumaric acid can be explained by evaporation of 2,6-lutidine from the structure, suggesting it is appropriate to think of this structure as behaving more like a solvate than a salt. Solution-state ${ }^{1} \mathrm{H}$ NMR of samples that had been stored as powders under ambient conditions showed a small decrease in the ratio of 2,6-lutidine to

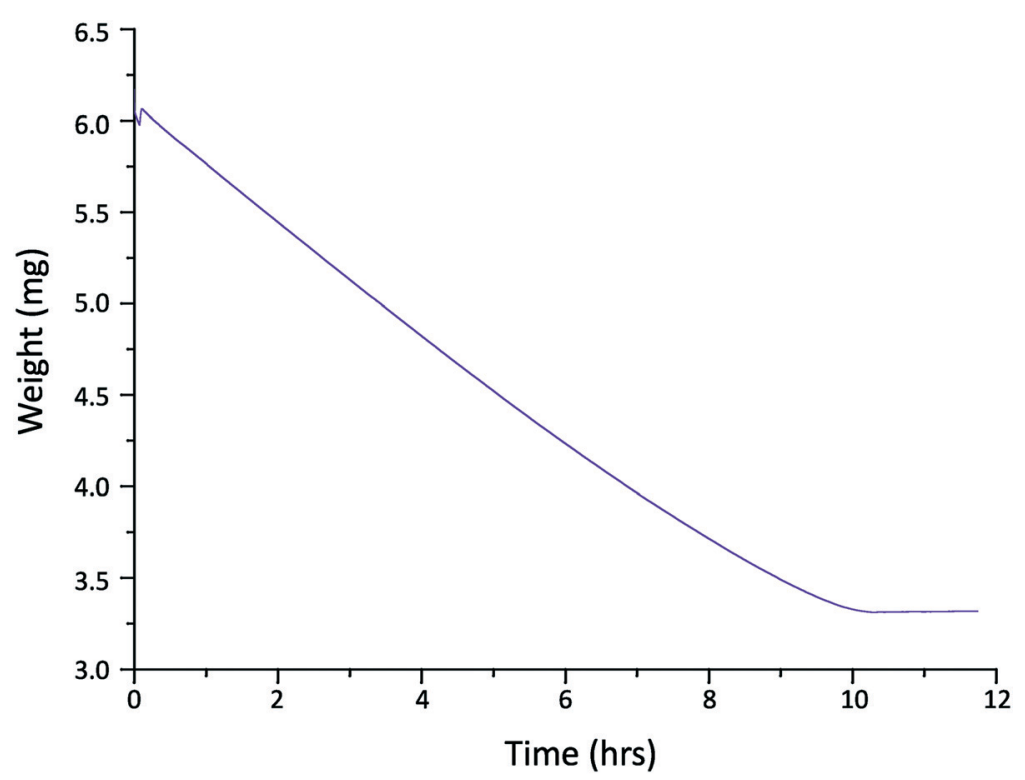

Fig. 11 TGA of 2,6-lutidinium hydrogen fumarate powder recorded on a Mettler Toledo Star ${ }^{\mathrm{e}}$ instrument with a ramp of $10{ }^{\circ} \mathrm{C} \mathrm{min}^{-1}$ from $25-70$ ${ }^{\circ} \mathrm{C}$. The sample was then held at $70{ }^{\circ} \mathrm{C}$ for 12 hours. 
fumaric acid compared to either a freshly ground powder or a dissolved single crystal (Fig. S6†). Storage as single crystals did not result in measurable degradation of the salt or formation of fumaric acid by XRD or MAS NMR, even over the course of several months. The apparent relative stability of the single crystals compared to powdered samples implies gradual evaporation of the 2,6-lutidine from the crystal surface, negligible at the relatively smaller surface area to volume ratio of single crystals compared to a crystallite within the powder. As 2,6-lutidinium sits in stacks through the structure, we speculate that the loss of 2,6-lutidine through evaporation would leave wide pores in the remaining structure that only contains fumaric acid, resulting in collapse of the structure to the more stable crystalline fumaric acid form. It is unclear at what stage transfer of a proton from 2,6-lutidinium to hydrogen fumarate occurs, as is required for the packing within the crystalline fumaric acid structure of neutral molecules rather than hydrogen fumarate ions.

Differential scanning calorimetry (DSC) data for 2,6lutidinium hydrogen fumarate showed no evaporation with only a single melting point at $112{ }^{\circ} \mathrm{C}$ (Fig. S7†). This falls in between the melting points of lutidine and fumaric acid ( -6 and $298{ }^{\circ} \mathrm{C}$, respectively) as expected for a multicomponent structure. As the boiling point of 2,6-lutidine is $143{ }^{\circ} \mathrm{C}$, any evaporation would be expected to be slow and so unlikely to be evident relative to a speed of heating of $10{ }^{\circ} \mathrm{C} \mathrm{min}^{-1}$. Thermogravimetric analysis (TGA) of powdered 2,6-lutidinium hydrogen fumarate held at $70{ }^{\circ} \mathrm{C}$ for $12 \mathrm{~h}$ showed a gradual loss in mass over the first $10 \mathrm{~h}$, which then plateaued (Fig. 11). The loss in mass corresponds to $96.3 \%$ of the 2,6-lutidine that was present in the complete crystal structure originally. If the mass loss is due to evaporation of 2,6lutidine, as proposed, the plateau prior to complete loss suggests that the remaining $3.7 \%$ of 2,6 -lutidine molecules are trapped in the centre of the crystallites, with insufficient energy at $70^{\circ} \mathrm{C}$ to escape. This could be due to the collapse of the majority of the structure preventing evaporation of this residual $3.7 \%$ of 2,6 -lutidine molecules.

\section{Conclusions}

A combined NMR and XRD crystallographic investigation of 2,6-lutidinium hydrogen fumarate has been presented together with a computational study based on DFT geometry optimisation and GIPAW calculation of NMR chemical shifts.

The use of this combined approach enabled the identification of fumaric acid formation within powder samples over time. Based on a corresponding reduction in the ratio of 2,6-lutidine to fumaric acid (by solution-state NMR) and significant weight loss of a sample at $70{ }^{\circ} \mathrm{C}$ (as observed by solution-state NMR and TGA analysis, respectively), it is proposed that this is due to slow evaporation of 2,6-lutidine, which is liquid at room temperature, from the crystal structure. It was not possible to determine the formation of fumaric acid solely by PXRD as both reflection overlap and splittings present in the in-house data prevented a multiphase refinement, making the addition of solid-state NMR analysis crucial to understanding the structure's stability. This highlights both the complementarity of XRD and NMR methods and also the benefits of following a multitechnique crystallographic approach.

2,6-Lutidinium hydrogen fumarate was found to form plate crystals and to undergo a skewed unit cell contraction at low temperatures. A second room temperature structure, CCDC 1876100, was also identified by SXRD. This shows a similar variation in unit cell parameters to the $100 \mathrm{~K}$ structure, both in the contraction along $a$ and $b$ axes and in the skew of the $\beta$ angle. Although it may exist as a minor component within the crystalline powder, it is unlikely to have any significant effect on the physical properties as the changes in the relative atomic positions compared to the previously published structure are so small. This results in only very small changes in the GIPAW calculated chemical shifts, suggesting it is invisible to solid-state NMR.

With the increasing development of APIs and AIs that require formulation into more complex multicomponent forms, an improved understanding of the limitations and complementarities of the individual analytical techniques used to characterise them is of great importance.

\section{Conflicts of interest}

There are no conflicts to declare.

\section{Acknowledgements}

We thank Dr Guy Clarkson and Dr Steven Huband for their assistance with in house XRD analysis. Crystallographic data were collected using an instrument that received funding from the European Research Council (ERC) under the European Union's Horizon 2020 research and innovation programme (grant agreement No 637313, PI: Adrian Chaplin, Chemistry, University of Warwick). The I11 beamtime was obtained through the Diamond Light Source Block Allocation Group award "Oxford/Warwick Solid State Chemistry BAG to probe composition-structure-property relationships in solids" (EE18786) and we thank Dr Claire Murray, Dr Mark Senn and Mr Gabriel Clarke for their assistance with measuring the data. Emily Corlett thanks EPSRC, AstraZeneca and Syngenta for a PhD studentship through the EPSRC Centre for Doctoral Training in Molecular Analytical Science, grant number EP/ L015307/1.

The calculated and experimental data for this study are provided as a supporting data set from WRAP, the Warwick Research Archive Portal at http://wrap.warwick.ac.uk/117210.

\section{References}

1 L. A. E. Sousa, S. M. Reutzel-Edens, G. A. Stephenson and L. S. Taylor, Mol. Pharmaceutics, 2015, 12, 484-495.

2 R. Thakuria, A. Delori, W. Jones, M. P. Lipert, L. Roy and N. Rodriguez-Hornedo, Int. J. Pharm., 2013, 453, 101-125. 
3 P. C. Vioglio, M. R. Chierotti and R. Gobetto, Adv. Drug Delivery Rev., 2017, 117, 86-110.

4 N. Blagden, M. de Matas, P. T. Gavan and P. York, Adv. Drug Delivery Rev., 2007, 59, 617-630.

5 S. Mohamed, D. A. Tocher, M. Vickers, P. G. Karamertzanis and S. L. Price, Cryst. Growth Des., 2009, 9, 2881-2889.

6 V. R. Hathwar, R. Pal and T. N. G. Row, Cryst. Growth Des., 2010, 10, 3306-3310.

7 J. D. Dunitz, CrystEngComm, 2003, 5, 506-506.

8 D. J. Berry and J. W. Steed, Adv. Drug Delivery Rev., 2017, 117, 3-24.

9 D. V. Dudenko, P. A. Williams, C. E. Hughes, O. N. Antzutkin, S. P. Velaga, S. P. Brown and K. D. M. Harris, J. Phys. Chem. C, 2013, 117, 12258-12265.

10 D. Ludeker and G. Brunklaus, Solid State Nucl. Magn. Reson., 2015, 65, 29-40.

11 E. Tedesco, S. S. Dhillon, K. D. M. Harris, R. L. Johnston, G. W. Turner, B. M. Kariuki, R. Delhez and E. J. Mittemeijer, Mater. Sci. Forum, 2001, 378-383, 784-788.

12 K. D. M. Harris, R. L. Johnston, B. M. Kariuki, E. Tedesco, G. W. Turner, R. Delhez and E. J. Mittemeijer, Mater. Sci. Forum, 2001, 378-383, 38-46.

13 M. Brunelli, J. P. Wright, G. R. M. Vaughan, A. J. Mora and A. N. Fitch, Angew. Chem., Int. Ed., 2003, 42, 2029-2032.

14 L. Smrcok, M. Brunelli, M. Boca and M. Kucharik, J. Appl. Crystallogr., 2008, 41, 634-636.

15 S. E. Ashbrook and D. McKay, Chem. Commun., 2016, 52, 7186-7204.

16 B. Elena, G. Pintacuda, N. Mifsud and L. Emsley, J. Am. Chem. Soc., 2006, 128, 9555-9560.

17 R. K. Harris, Solid State Sci., 2004, 6, 1025-1037.

18 C. Bonhomme, C. Gervais, F. Babonneau, C. Coelho, F. Pourpoint, T. Azais, S. Ashbrook, J. Griffin, J. Yates, F. Mauri and C. Pickard, Chem. Rev., 2012, 112, 5733-5779.

19 T. Charpentier, Solid State Nucl. Magn. Reson., 2011, 40, $1-20$.

20 C. J. Pickard and F. Mauri, Phys. Rev. B: Condens. Matter Mater. Phys., 2001, 63, 245101.

21 J. Yates, C. Pickard and F. Mauri, Phys. Rev. B: Condens. Matter Mater. Phys., 2007, 76, 024401.

22 J. K. Harper, R. Iuliucci, M. Gruber and K. Kalakewich, CrystEngComm, 2013, 15, 8693-8704.

23 P. Paluch, T. Pawlak, M. Oszajca, W. Lasocha and M. J. Potrzebowski, Solid State Nucl. Magn. Reson., 2015, 65, 2-11.

24 N. J. Vigilante and M. A. Mehta, Acta Crystallogr., Sect. C: Struct. Chem., 2017, 73, 234-243.

25 D. V. Dudenko, J. R. Yates, K. D. M. Harris and S. P. Brown, CrystEngComm, 2013, 15, 8797-8807.

26 M. R. Chierotti and R. Gobetto, CrystEngComm, 2013, 15, 8599-8612.

27 A. C. Poppler, E. K. Corlett, H. Pearce, M. P. Seymour, M. Reid, M. G. Montgomery and S. P. Brown, Acta Crystallogr., Sect. C: Struct. Chem., 2017, 73, 149-156.
28 J. R. Yates, T. N. Pham, C. J. Pickard, F. Mauri, A. M. Amado, A. Gil and S. P. Brown, J. Am. Chem. Soc., 2005, 127, 10216-10220.

29 P. Florian and D. Massiot, CrystEngComm, 2013, 15, 8623-8626.

30 S. P. Brown, Solid State Nucl. Magn. Reson., 2012, 41, 1-27.

31 Y. J. Pan, Z. M. Jin, C. R. Sun and C. W. Jiang, Chem. Lett., 2001, 30, 1008-1009.

32 British National Formulary, The National Institute for Health and Care Excellence (NICE), http://bnf.nice.org.uk/, 2018.

33 D. A. Haynes, W. Jones and W. D. S. Motherwell, CrystEngComm, 2006, 8, 830-840.

34 S. J. Clark, M. D. Segall, C. J. Pickard, P. J. Hasnip, M. J. Probert, K. Refson and M. C. Payne, Z. Kristallogr., 2005, 220, 567-570.

35 J. P. Perdew, K. Burke and M. Ernzerhof, Phys. Rev. Lett., 1996, 77, 3865-3868.

36 C. R. Groom, I. J. Bruno, M. P. Lightfoot and S. C. Ward, Acta Crystallogr., Sect. B: Struct. Sci., Cryst. Eng. Mater., 2016, 72, 171-179.

37 A. Tkatchenko and M. Scheffler, Phys. Rev. Lett., 2009, 102, 073005 .

38 I. J. Bruno, J. C. Cole, M. Kessler, J. Luo, W. D. S. Motherwell, L. H. Purkis, B. R. Smith, R. Taylor, R. I. Cooper, S. E. Harris and A. G. Orpen, J. Chem. Inf. Comput. Sci., 2004, 44, 2133-2144.

39 A. C. Poppler, D. Walker and S. P. Brown, CrystEngComm, 2017, 19, 224-236.

40 G. N. M. Reddy, D. S. Cook, D. Iuga, R. I. Walton, A. Marsh and S. P. Brown, Solid State Nucl. Magn. Reson., 2015, 65, 41-48.

41 R. K. Harris, P. Hodgkinson, C. J. Pickard, J. R. Yates and V. Zorin, Magn. Reson. Chem., 2007, 45, S174-S186.

42 T. Venâncio, L. M. Oliveira, J. Ellena, N. Boechat and S. P. Brown, Solid State Nucl. Magn. Reson., 2017, 87, 73-79.

43 F. M. Paruzzo, A. Hofstetter, F. Musil, S. De, M. Ceriotti and L. Emsley, Nat. Commun., 2018, 9, 4501.

44 J. D. Hartman, R. A. Kudla, G. M. Day, L. J. Mueller and G. J. O. Beran, Phys. Chem. Chem. Phys., 2016, 18, 21686-21709.

45 M. Zilka, S. Sturniolo, S. P. Brown and J. R. Yates, J. Chem. Phys., 2017, 147, 144203.

46 Agilent, CrysAlisPRO, Agilent Technologies Ltd., 2014.

47 G. M. Sheldrick, Acta Crystallogr., Sect. A: Found. Crystallogr., 2008, 64, 112-122.

48 O. V. Dolomanov, L. J. Bourhis, R. J. Gildea, J. A. K. Howard and H. Puschmann, J. Appl. Crystallogr., 2009, 42, 339-341.

49 A. A. Coehlo, TOPAS-Academic V6, Coelho Software, 2016.

50 A. Le Bail, H. Duroy and J. L. Fourquet, Mater. Res. Bull., 1988, 23, 447-452.

51 H. M. Rietveld, J. Appl. Crystallogr., 1969, 2, 65-71.

52 D. Sakellariou, A. Lesage, P. Hodgkinson and L. Emsley, Chem. Phys. Lett., 2000, 319, 253-260.

53 B. Elena, G. de Paepe and L. Emsley, Chem. Phys. Lett., 2004, 398, 532-538. 
54 B. M. Fung, A. K. Khitrin and K. Ermolaev, J. Magn. Reson., 2000, 142, 97-101.

55 G. Metz, X. L. Wu and S. O. Smith, J. Magn. Reson., Ser. A, 1994, 110, 219-227.

56 W. Sommer, J. Gottwald, D. E. Demco and H. W. Spiess, J. Magn. Reson., Ser. A, 1995, 113, 131-134.

57 I. Schnell, A. Lupulescu, S. Hafner, D. E. Demco and H. W. Spiess, J. Magn. Reson., 1998, 133, 61-69.

58 S. Cavadini, S. Antonijevic, A. Lupulescu and G. Bodenhausen, J. Magn. Reson., 2006, 182, 168-172.

59 S. Cavadini, Prog. Nucl. Magn. Reson. Spectrosc., 2010, 56, 46-77.

60 A. S. Tatton, J. P. Bradley, D. Iuga and S. P. Brown, Z. Phys. Chem., 2012, 226, 1187-1203.

61 Z. H. Gan, J. P. Amoureux and J. Trebosc, Chem. Phys. Lett., 2007, 435, 163-169.

62 M. H. Levitt, T. G. Oas and R. G. Griffin, Isr. J. Chem., 1988, 28, 271-282.

63 T. G. Oas, R. G. Griffin and M. H. Levitt, J. Chem. Phys., 1988, 89, 692-695.

64 D. Marion, M. Ikura, R. Tschudin and A. Bax, J. Magn. Reson., 1989, 85, 393-399.

65 S. Hayashi and K. Hayamizu, Bull. Chem. Soc. Jpn., 1991, 64, 685-687.

66 C. R. Morcombe and K. W. Zilm, J. Magn. Reson., 2003, 162, 479-486.

67 S. Hayashi and K. Hayamizu, Bull. Chem. Soc. Jpn., 1991, 64, 688-690.

68 R. K. Harris, P. Y. Ghi, H. Puschmann, D. C. Apperley, U. J. Griesser, R. B. Hammond, C. Y. Ma, K. J. Roberts, G. J. Pearce, J. R. Yates and C. J. Pickard, Org. Process Res. Dev., 2005, 9, 902-910.
69 J. R. Yates, S. E. Dobbins, C. J. Pickard, F. Mauri, P. Y. Ghi and R. K. Harris, Phys. Chem. Chem. Phys., 2005, 7, 1402-1407.

70 A. L. Webber, L. Emsley, R. M. Claramunt and S. P. Brown, J. Phys. Chem. A, 2010, 114, 10435-10442.

71 X. Li, L. Tapmeyer, M. Bolte and J. van de Streek, ChemPhysChem, 2016, 17, 2496-2502.

72 L. Mafra, S. M. Santos, R. Siegel, I. Alves, F. A. A. Paz, D. Dudenko and H. W. Spiess, J. Am. Chem. Soc., 2012, 134, 71-74.

73 J. Schmidt, A. Hoffmann, H. W. Spiess and D. Sebastiani, J. Phys. Chem. B, 2006, 110, 23204-23210.

74 C. Gervais, M. Profeta, V. Lafond, C. Bonhomme, T. Azaïs, H. Mutin, C. J. Pickard, F. Mauri and F. Babonneau, Magn. Reson. Chem., 2004, 42, 445-452.

75 A. C. Uldry, J. M. Griffin, J. R. Yates, M. Perez-Torralba, M. D. Maria, A. L. Webber, M. L. L. Beaumont, A. Samoson, R. M. Claramunt, C. J. Pickard and S. P. Brown, J. Am. Chem. Soc., 2008, 130, 945-954.

76 C. M. Gowda, F. Vasconcelos, E. Schwartz, E. R. H. van Eck, M. Marsman, J. J. L. M. Cornelissen, A. E. Rowan, G. A. de Wijs and A. P. M. Kentgens, Phys. Chem. Chem. Phys., 2011, 13, 13082-13095.

77 S. P. Brown, Prog. Nucl. Magn. Reson. Spectrosc., 2007, 50, 199-251.

78 S. P. Brown, in Modern Methods in Solid-state NMR: A Practitioner's Guide, ed. P. Hodgkinson, Royal Society of Chemistry, London, 2018, ch. 2, pp. 39-74.

79 R. K. Harris, P. Jackson, L. H. Merwin, B. J. Say and G. Hagele, J. Chem. Soc., Faraday Trans. 1, 1988, 84, 3649-3672.

80 L. H. Merwin and S. D. Ross, Magn. Reson. Chem., 1992, 30, 440-448.

81 A. L. Bednowitz and B. Post, Acta Crystallogr., 1966, 21, 566-571. 